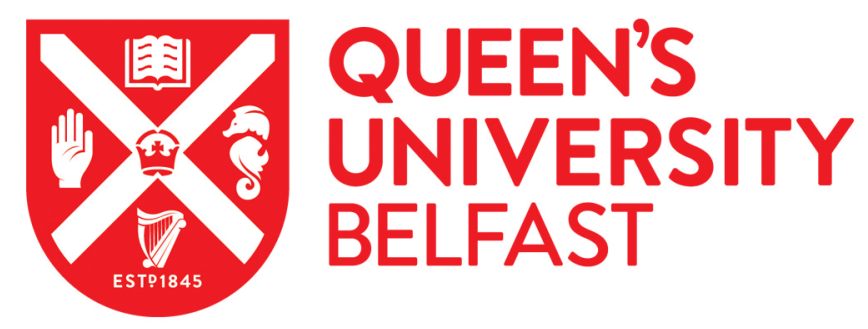

\title{
Fracture toughness and crack resistance curves for fiber compressive failure mode in polymer composites under high rate loading
}

Kuhn, P., Catalanotti, G., Xavier, J., Camanho, P. P., \& Koerber, H. (2017). Fracture toughness and crack resistance curves for fiber compressive failure mode in polymer composites under high rate loading. Composite Structures, 182, 164-175. https://doi.org/10.1016/j.compstruct.2017.09.040

Published in:

Composite Structures

Document Version:

Peer reviewed version

Queen's University Belfast - Research Portal:

Link to publication record in Queen's University Belfast Research Portal

\section{Publisher rights}

Copyright 2017 Elsevier.

This manuscript is distributed under a Creative Commons Attribution-NonCommercial-NoDerivs License

(https://creativecommons.org/licenses/by-nc-nd/4.0/), which permits distribution and reproduction for non-commercial purposes, provided the author and source are cited.

\section{General rights}

Copyright for the publications made accessible via the Queen's University Belfast Research Portal is retained by the author(s) and / or other copyright owners and it is a condition of accessing these publications that users recognise and abide by the legal requirements associated with these rights.

Take down policy

The Research Portal is Queen's institutional repository that provides access to Queen's research output. Every effort has been made to ensure that content in the Research Portal does not infringe any person's rights, or applicable UK laws. If you discover content in the Research Portal that you believe breaches copyright or violates any law, please contact openaccess@qub.ac.uk. 


\section{Accepted Manuscript}

Fracture toughness and crack resistance curves for fiber compressive failure mode in polymer composites under high rate loading

P. Kuhn, G. Catalanotti, J. Xavier, P.P. Camanho, H. Koerber

PII:

$$
\text { S0263-8223(17)32082-2 }
$$

DOI: http://dx.doi.org/10.1016/j.compstruct.2017.09.040

Reference: COST 8903

To appear in:

\section{Composite Structures}

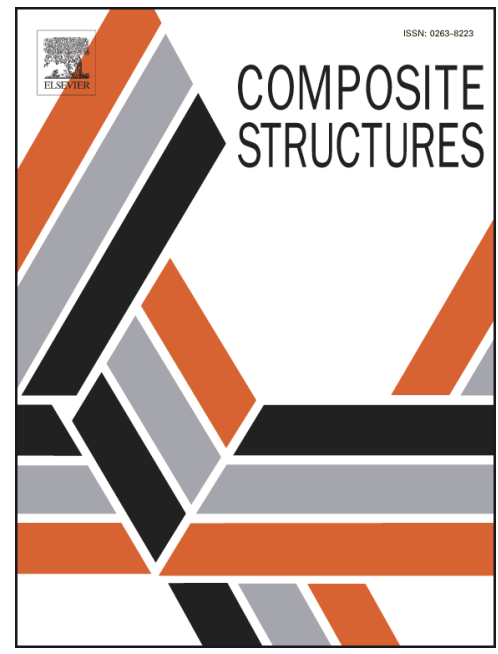

Received Date: $\quad 6$ July 2017

Revised Date: $\quad 15$ September 2017

Accepted Date: $\quad 16$ September 2017

Please cite this article as: Kuhn, P., Catalanotti, G., Xavier, J., Camanho, P.P., Koerber, H., Fracture toughness and crack resistance curves for fiber compressive failure mode in polymer composites under high rate loading, Composite Structures (2017), doi: http://dx.doi.org/10.1016/j.compstruct.2017.09.040

This is a PDF file of an unedited manuscript that has been accepted for publication. As a service to our customers we are providing this early version of the manuscript. The manuscript will undergo copyediting, typesetting, and review of the resulting proof before it is published in its final form. Please note that during the production process errors may be discovered which could affect the content, and all legal disclaimers that apply to the journal pertain. 


\title{
Fracture toughness and crack resistance curves for fiber compressive failure mode in polymer composites under high rate loading
}

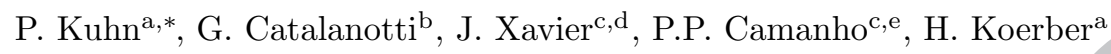 \\ ${ }^{a}$ Technical University of Munich, Department of Mechanical Engineering, Chair for Carbon \\ Composites, Boltzmannstraße 15, 85748 Garching, Germany \\ ${ }^{b}$ School of Mechanical and Aerospace Engineering, Queen's University Belfast, United \\ Kingdom \\ ${ }^{c}$ INEGI, Institute of Science and Innovation in Mechanical and Industrial Engineering, \\ Rua Dr. Roberto Frias 400, 4200-465 Porto, Portugal \\ ${ }^{d}$ CITAB, University of Tras-os-Montes e Alto Douro, UTAD, Quinta de Prados, 5000-801 \\ Vila Real, Portugal \\ ${ }^{e}$ DEMec, Faculdade de Engenharia, Universidade do Porto, Rua Dr. Roberto Frias, \\ 4200-65 Porto, Portugal
}

\begin{abstract}
This work presents an experimental method to measure the compressive crack resistance curve of fiber-reinforced polymer composites when subjected to dynamic loading. The data reduction couples the concepts of energy release rate, size effect law and R-curve. Double-edge notched specimens of four different sizes are used. Both split-Hopkinson pressure bar and quasi-static reference tests are performed. The full crack resistance curves at both investigated strain rate regimes are obtained on the basis of quasi-static fracture analysis theory. The results show that the steady state fracture toughness of the fiber compressive failure mode of the unidirectional carbon-epoxy composite material IM78552 is $165.6 \mathrm{~kJ} / \mathrm{m}^{2}$ and $101.6 \mathrm{~kJ} / \mathrm{m}^{2}$ under dynamic and quasi-static loading, respectively. Therefore the intralaminar fracture toughness in compression is found to increase with increasing strain rate.
\end{abstract}

Keywords: Fiber-reinforced composites, R-curve, Dynamic fracture, Size effect

*Corresponding author. Tel.: +49 8928915096; Fax: +49 8928915097. E-mail address: kuhn@lcc.mw.tum.de (P. Kuhn)

Preprint submitted to Journal of Composite Structures 


\section{Introduction}

Recently proposed strength analysis methods [1, 2, 3, 4, 5, require the specification of fracture toughness parameters associated to the main failure modes in order to predict damage evolution after the material strength has been reached.

${ }_{5}$ The softening laws used in the material models with progressive damage are dictated by the crack resistance curves (R-curves) [6] and therefore-reliable experimental methods to measure the fracture toughnesses and corresponding crack resistance curves are needed.

While well established static test standards and procedures are available for the interlaminar matrix failure modes [7, 8, 9], no test standards exist to measure the intralaminar fracture toughness associated with the longitudinal failure of fiber-reinforced composites. Pinho et al. [10] suggested Compact Tension (CT) and Compact Compression (CC) tests to obtain fracture toughness values for fiber tensile and fiber compressive failure, respectively. However, the $\mathrm{CC}$ test specimen is inadequate to measure the R-curve, since i) the kink band onset and propagation is accompanied by secondary damage mechanisms (e.g. delamination) that are neglected and will results in a exaggerated estimation of the fracture toughness; ii) the crack tip cannot be easily identified; iii) the tractions within the fracture process zone are not taken into account properly [11. Hence only the initiation value for the fiber compressive fracture toughness can be measured confidently using the CC specimen. Similar work has been done by Zobeiry et al. [12, testing CC and over-heigth compact tension (OCT) specimens with a quasi-isotropic layup. Initiation values for compressive fracture toughness of polymer composites have also been obtained by Laffan et al. 13] using a four-point bending configuration. Soutis et al. [14 tested multidirectional centre-notched compression specimens with various layups and notch lengths to investigate the influence of the number of $0^{\circ}$ plies on the laminate compressive fracture toughness. To overcome the limitations of the $\mathrm{CC}$ test method, Catalanotti et al. [15] proposed a static test method using double-edge notched (DEN) specimens and the relation between the size effect law and the 
R-curve. In follow-up works, the method was extended to tensile [16] and shear loading [17] and recently used by Pinto et al. [18] to measure the intralaminar crack resistance curves at extreme temperatures.

Taking into account that automotive and aeronautical polymer composite structures are subjected to dynamic loading scenarios (e.g. crash, foreign object impact), strain rate effects should be captured by advanced composite material models to predict initiation and evolution of damage accurately. The strain rate sensitivity of the stiffness and strength components of polymer composites has been intensively investigated and reviewed over the last decades [19, 20]. In addition, the experimental investigation of the dynamic interlaminar fracture toughnesses has received significant attention, motivated by the need to understand the delamination damage within composite laminates after low-energy impact. Published work on dynamic interlaminar fracture toughness was summarized by Jacob et al. 21], concluding that there is no agreement, either, on

45 the trend of frature toughness with regard to strain rate or on the best suitable experimental and analysis procedure.

In contrast to the interlaminar fracture modes, very little is known regarding the effect of dynamic loading on the energy intensive intralaminar fiber failure modes. McCarroll [22] used a servo-hydraulic machine to test carbon-epoxy CT specimens at cross-head velocities up to $12 \mathrm{~m} / \mathrm{s}$. With increasing loading speed, a possible small decrease of the intralaminar fiber tensile fracture toughness was found. However, the range of values was within the scatter of the results.

Therefore, there is the need to develop experimental methods to measure the intralaminar fracture toughness in a dynamic loading scenario. In the presented work, the methodology proposed by Catalanotti et al. [15] to measure the mode I intralaminar R-curve in compression is extended to the case of dynamic loading. This approach uses the relations between the size effect law, initially proposed by Bažant and Planas [23, the energy release rate (ERR) and the R-curve. The method does not require the optical measurement of crack length, whose determination is found to be a main source of errors in fracture mechanic tests [24, and is particularly critical for high loading rate experiments, where 
high speed cameras with reduced resolution are used. The dynamic tests are conducted on a split-Hopkinson pressure bar (SHPB), which is a widely-used setup for dynamic fracture tests [25]. Following Catalanotti et al. [15, doubleedge notched compression (DENC) specimens are used for the determination of the size effect law. This specimen type is well suited for SHPB testing, as it is found to be nonsensitive to complex wave deflections that might cause undesirable mixed mode stress state during the loading of the specimen.

\section{Analysis scheme}

The analysis scheme of this work is based on the relations between the energy release rate, the R-curve and the size effect law. According to Bažant and Planas [23, if the energy release rate is an increasing function of the crack length (the specimen has a positive geometry) the ERR-curves $G_{I}$ for different specimen sizes $w_{k}$, corresponding to the peak loads $P_{u k}$, are tangent to the R-curve $R$

75 (Fig. 11. This relation can be used to measure the intralaminar R-curves of fiber reinforced polymers, as shown by Catalanotti et al. [15, 16].

\section{[Figure 1 about here]}

The energy release rate $G_{I}$ in a balanced cross-ply laminate (with $x$ and $y$ as the preferred axes of the material) under tensile or compressive loading normal to the fracture surface (mode I) reads, for a crack propagating along $x$ [26]:

$$
G_{I}=\frac{1}{E} \sqrt{\frac{1+\rho}{2}} K_{I}^{2}
$$

where $E$ denotes the laminate Young's modulus $\left(E=E_{x}=E_{y}\right), K_{I}$ is the stress intensity factor and $\rho$ is the dimensionless elastic parameter defined as [26]:

$$
\rho=\frac{2 s_{12}+s_{66}}{2 \sqrt{s_{11} s_{22}}}
$$

where $s_{l m}$ are the components of the compliance matrix computed in the $x-y$ coordinate system. The stress intensity factor, $K_{I}$ in Eq. (1), depends on the 
specimen geometry and can be written for a double edge notched specimen (Fig. 2) as [26, 27]:

$$
K_{I}=\sigma \sqrt{w} \sqrt{\phi(\alpha, \rho)}
$$

in which $\sigma$ is the remote stress, $w$ is the characteristic size of the specimen (see Fig. 22 and $\phi(\alpha, \rho)$ is the dimensionless correction function for geometry and orthotropy including the shape parameter $\alpha=a / w$. Replacing Eq. (3) in Eq.

$90 \quad(1), G_{I}$ yields:

$$
G_{I}(a+\Delta a)=\frac{1}{E} \sqrt{\frac{1+\rho}{2}} w \sigma^{2} \phi\left(\alpha_{0}+\frac{\Delta a}{w}, \rho\right)
$$

where $\alpha_{0}=a_{0} / w$ is the initial shape parameter (see Fig. 2) and $\Delta a$ is the crack increment.

\section{[Figure 2 about here]}

Since there are not analytical solutions available, $\phi(\alpha, \rho)$ can be calculated numerically by applying the Virtual Crack Closure Technique (VCCT) [28]. Following [15], a two-dimensional Finite Element Model of the DENC specimen is built in the commercial software Abaqus [29] using 4-node reduced integration elements (CPS4R) with assigned elastic properties of the laminate (Fig. 3). The energy release rate, calculated with the $\mathrm{VCCT}$, is equal to:

$$
G_{I}\left(a^{\star}, \rho\right)=Y_{m}\left(a^{\star}, \rho\right) u_{n}\left(a^{\star}, \rho\right) / l_{e}
$$

where $a^{\star}$ is the crack length of the given FE model, $Y_{m}$ and $u_{n}$ are the load and the displacement in the y-direction of the nodes $m$ and $n$, respectively, and $l_{e}$ is the element length in x-direction (see Fig. 3). Replacing $G_{I}\left(a^{\star}, \rho\right)$ in Eq. (4) yields $\phi\left(\alpha^{\star}, \rho\right)$. Repeating this calculation for several $\alpha^{\star}$ using a parametric model, and fitting the numerical point using a polynomial fitting function allows the calculation of $\phi(\alpha, \rho)$.

[Figure 3 about here]

The approach proposed by Bažant and Planas [23, that the crack driving force curve $G_{I}$ at the peak load $P_{u}$ is tangent to the R-curve $R$, is described by 
the following system of equations:

$$
\left\{\begin{array}{c}
G_{I}(\Delta a)=R(\Delta a) \\
\frac{\partial G_{I}(\Delta a)}{\partial \Delta a}=\frac{\partial R(\Delta a)}{\partial \Delta a} .
\end{array}\right.
$$

Using the ultimate nominal stress, $\sigma_{u}=P_{u} /(2 w t)$, where $t$ is the laminate thickness, and assuming that the size effect law,$\sigma_{u}=\sigma_{u}(w)$, is known, substituting Eq. (4) in the first of Eq. (6) results in:

$$
\frac{1}{E} \sqrt{\frac{1+\rho}{2}} w \sigma_{u}^{2} \phi\left(\alpha_{0}+\frac{\Delta a}{w}, \rho\right)=R(\Delta a)
$$

which holds for every specimen size $w$. Remembering that, by definition, the R-curve does not depend on the spezimen size $\mathrm{w}(\partial R / \partial w=0)$ and assuming that geometrically similar specimens are tested $\left(\alpha_{0}\right.$ is not a function of $w$ ) [23, the second of Eq. (6) yields:

$$
\frac{1}{E} \sqrt{\frac{1+\rho}{2}} \frac{\partial}{\partial w}\left(w \sigma_{u}^{2} \phi\left(\alpha_{0}+\frac{\Delta a}{w}, \rho\right)\right)=0 .
$$

Eq. (8) can be solved for $w=w(\Delta a)$ and replacing this solution in Eq. (7) yields the R-curve, $R(\Delta a)$. Visually, the R-curve is the envelope of the crack driving force curves at the peak load (see Fig. 1).

The described method provides the R-curve of the laminate. In fiber reinforced polymers the fracture toughness of the fiber failure modes is much higher than for matrix failure modes that can therefore be neglected [30]. This consideration is also true for interlaminar damage. It should be emphasized that in the experimental results presented in the following no extensive delamination was observed; therefore, it can be assumed confidently that the energy dissipated in the crack propagation is mainly due to the damage of the fiber. Hence, for a balanced cross-ply laminate, the R-curve of the $0^{\circ}$ plies, $R_{0}(\Delta a)$, can be estimated, from the energy balance, as twice of the laminates R-Curve, $R(\Delta a)$, without a significant loss of accuracy [10]. 


\section{Material and experimental procedures}

\subsection{Material and test specimens}

The carbon-epoxy prepreg material system HexPly IM7-8552, which is commonly used in primary aerospace structures, was selected for this work. In accordance with the specified heat cycle [31, a panel with a $[0 / 90]_{8 s}$ layup and a nominal thickness of $4 \mathrm{~mm}$ was cured in a hot press.

From the manufactured panel, double-edge notched compression (DENC) specimens were machined using a $1 \mathrm{~mm}$ diameter milling tool. A constant ratio of the geometric properties (length, width, initial crack length $a_{0}$ ) was held for all different specimen sizes (Fig. 4). The dimensions of the specimens were adopted from [15]. The shape of the initial crack tip does not affect the correct determination of the R-curve [16, 32] and was constant (semicircular, $1 \mathrm{~mm}$ of diameter) for all specimens. To enable the use of digital image correlation (DIC), the specimens were prepared by applying a random black-on-white speckle pattern.

Table 1 shows the elastic properties of the laminate under quasi-static (QS) and high strain rate $\left(\mathrm{HR}, \dot{\epsilon}_{s} \approx 100 \mathrm{~s}^{-1}\right)$ conditions. The Young's modulus $E$ and the Poisson's ratio $\nu_{x y}$ of the balanced cross-ply were obtained by separate compression tests with unnotched specimens and no strain rate sensitivity was found for $E$. The in-plane shear modulus $G_{x y}$ was calculated accordingly to the classical lamination theory using as reference the values found in [33.

[Table 1 about here]

\subsection{Quasi-static experimental setup}

The quasi-static (QS) reference tests were carried out on a standard electromechanical testing machine (Hegewald \& Peschke Inspect Table 100), equipped with a $100 \mathrm{kN}$ load cell. The tests were conducted under displacement control 
and a cross-head displacement rate of $0.15 \mathrm{~mm} / \mathrm{min}$ was imposed. A self alignment device as described in [33] was used and friction between the loading parts and the specimen end-surfaces was minimized by a thin layer of molybdenum disulphide $\left(\mathrm{MoS}_{2}\right)$ paste.

The GOM ARAMIS-4M optical system was used for DIC measurement of the three-dimensional in plane strain field. It consisted of two CCD cameras with a resolution of $1728 \times 2352$ pixel $^{2}$, adjusted to capture a measuring volume of $35 \times 26 \mathrm{~mm}^{2}$ (length $\times$ width). A frame rate of 1 frame per second (fps) was used together with a shutter speed of $50 \mathrm{~ms}$. Fig. 5 shows the quasi-static photomechanical setup.

[Figure 5 about here]

\subsection{Dynamic experimental setup}

The high strain rate (HR) compression tests were performed on a splitHopkinson pressure bar (SHPB) system, as illustrated in Figure 6. The lengths of the steel striker-, incident- and transmission bars were 0.6, 2.6 and $1.3 \mathrm{~m}$, respectively. The strain gauges on the incident-bar were located at $1.3 \mathrm{~m}$ and on the transmission bar at $0.3 \mathrm{~m}$ away from the bar-specimen interfaces. The bars diameter $d_{b}$ (Table 2) was adapted to the particular tested specimen width and 175 friction between the specimen and the bar end-faces was reduced by applying a thin layer of $\mathrm{MoS}_{2}$ paste. To ensure that the axial strain rate was the same for every specimen size, a Finite Element Model was used to set the SHPB configuration in terms of the striker velocity $v_{s}$ and the diameter $d_{P S}$ and thickness $t_{P S}$ of the copper pulse shaper (Table 2). Expecting a linear stress-strain behaviour of the specimens up to failure, a triangular shaped incident-wave is best suited to obtain nearly constant strain rates [34, 35]. The accuracy of the used SHPB system was ascertained by bars-together tests, documented in [36].

For the determination of the two-dimensional strain field using DIC, the specimen deformation was monitored by a single Photron FASTCAM SA-Z high speed camera. For all specimens, a frame rate of 300,000 fps with a corresponding resolution of $256 \times 128$ pixel $^{2}$ was chosen. 
[Figure 6 about here]

[Table 2 about here]

\subsection{Data reduction methods}

190

\subsubsection{Stress, strain and strain rate}

In the case of the quasi-static tests, the ultimate remote stress $\sigma_{u}$ was calculated by dividing the peak load $P_{u}$, measured from the load cell of the testing machine, by the specimen cross-section $A_{s}$, with $A_{s}=2 w t$.

For the high rate tests the axial stress component of the specimen $\sigma_{s}$ can be calculated with the classic split-Hopkinson pressure bar analysis (SHPBA) [37, 38, by using 1 -wave- and 2-wave-analysis:

$$
\begin{gathered}
\sigma_{s 1}=\frac{A_{b}}{A_{s}} E_{b} \varepsilon_{T} \\
\sigma_{s 2}=\frac{A_{b}}{A_{s}} E_{b}\left(\varepsilon_{I}+\varepsilon_{R}\right)
\end{gathered}
$$

where $A_{b}$ is the bar cross-section, $E_{b}$ is the Young's modulus of the bar material and $\varepsilon_{I}, \varepsilon_{R}, \varepsilon_{T}$ are the incident, reflected and transmitted bar strain waves, respectively. As both terms (Eq. 9, Eq. 10) were used to check and confirm specimen stress-equilibrium, ultimate remote stress was calculated just from Eq. 9. The transmission wave $\varepsilon_{T}$ in Eq. 9 has a smooth signal and dispersion effects in $\varepsilon_{T}$ are small due to the short distance between the bar-specimen interface and the strain gauge terminal on the transmission bar $(0.3 \mathrm{~m})$. Since the specimen strain $\varepsilon_{s}$ calculated from SHPBA tends to be over-predicted [39], specimen strain was obtained for all tests from the DIC Software GOM ARAMIS by calculating the nominal engineering strain between two facet points along the specimen center line, as illustrated in Figure 7 To ensure comparability, the same procedure was used to estimate the specimen strain in the quasi-static tests. The DIC analysis parameters were chosen accordingly to the resolutions of the camera images and are given in Table 3

[Figure 7 about here] 
[Table 3 about here]

The specimen strain was further used to obtain the specimen strain rate $\dot{\epsilon}_{s}$ in loading direction by applying finite differentiation:

$$
\dot{\epsilon}_{s}(t)=\frac{\varepsilon_{s}(t)-\varepsilon_{s}(t-\Delta t)}{\Delta t}
$$

in which $\Delta t$ is the timestep between two consecutive DIC images.

\subsubsection{Energy terms}

The analysis scheme of this work (see section 2) is based on the quasistatic fracture mechanics theory. According to Jiang and Vecchio [25], quasistatic fracture theory is applicable for dynamic fracture toughness measurements under the condition of stress equilibrium. In addition to this classical splitHopkinson bar equilibrium check (using Eq. 9 and Eq. 10), the energy terms of the specimens were calculated and analyzed by using DIC data. This analysis procedure therefore uses the true specimen deformation behaviour, obtained from the optical measurement. According to the law of conservation of energy for a continuum body, the balance of mechanical energy reads [40]:

$$
\mathcal{W}=\mathcal{U}+\mathcal{K}
$$

where $\mathcal{W}$ is the external work, which is stored in the structure as strain energy $\mathcal{U}$ and kinetic energy $\mathcal{K}$. When $\mathcal{K} \ll \mathcal{U}$ and fracture is the only energy-consuming process, quasi-static fracture mechanics theory is applicable [23]. Using the inplane strain vector obtained from DIC, the strain energy of the specimen $\mathcal{U}$ is the sum of the strain energy at each individual facet point $\mathcal{U}_{j}$ and can be calculated as:

$$
\mathcal{U}=\sum_{j} \mathcal{U}_{j}=\sum_{j} V_{j} \frac{1}{2}\left(E_{x} \varepsilon_{x j}^{2}+E_{y} \varepsilon_{y j}^{2}+G_{x y} \gamma_{x y j}^{2}\right)
$$

in which $\varepsilon_{x j}, \varepsilon_{y j}$ and $\gamma_{x y j}$ are the individual facet's transversal, longitudinal and shearing strain, respectively. $V_{j}$ is the associated volume of the individual facet point, regulated by the DIC analysis parameters (Table 3) and specimen's 

basis of the velocity field from DIC:

$$
\mathcal{K}=\sum_{j} \mathcal{K}_{j}=\sum_{j} \frac{1}{2} D V_{j}\left(v_{x j}^{2}+v_{y j}^{2}\right)
$$

where $v_{x j}$ and $v_{y j}$ are the individual facet's transversal and longitudinal velocity, respectively, and $D$ is the density of the laminate.

\section{Experimental results}

\subsection{Specimen deformation and failure}

For each specimen type and strain rate regime, three valid tests are performed. All specimens fail due to compressive fracture along the direction of the initial notch, as shown in Fig. 8(a) for two specimens of type C. The axial (Fig. 8(b)) and shear strain fields (Fig. 8(c)) show plausible axis-symmetric and point-symmetric strain distributions, respectively, indicating well aligned loading of the specimens. Good accordance can be found between the strain distributions at quasi-static and dynamic loading conditions, which denote that no complex stress state is caused in the dynamically tested specimens due to wave deflections. Particularly, no shear strain is detected in the region near the crack tip at the specimen center, which verifies the assumption of crack propagation as a result of mode I loading.

[Figure 8 about here]

\subsection{Stress-strain behaviour}

Fig. 9 shows representative stress-strain curves for the different specimen 255 sizes, tested at QS strain rate level (see Appendix A for all stress-strain curves). Nearly linear elastic behaviour is detected until the specimens failed by ultimate compressive failure at peak load.

[Figure 9 about here] 
In Fig. 10, characteristic bar strain wave groups of a SHPB-test are presponding strain rate curves for both investigated loading regimes are shown in Fig. 13 The strain rate of the QS tests is in the order between $2 \times 10^{-5} \mathrm{~s}^{-1}$ and $1 \times 10^{-4} \mathrm{~s}^{-1}$, which is a typical magnitude for quasi-static loading conditions [41. For the HR tests a nearly constant strain rate of about $100 \mathrm{~s}^{-1}$ was 285

\footnotetext{
${ }^{1}$ The chosen specimen type $\mathrm{C}$ was used for a number of other figures presented in this paper: Fig. 10 can be linked to Figs. 11,12 and 13
} 
[Figure 12 about here]

[Figure 13 about here]

Fig. 14 shows the plot of the ultimate stress $\sigma_{u}$ vs. the specimen size $w$. As a results of the size effect, the ultimate stress decreases with increasing specimen Table 3 and Figs. 9 and 12 . Under quasi-static loading, the kinetic energy $\mathcal{K}$ is quite constant at a very low level after initial acceleration (Fig. 15(c)). At failure, the ratio of $\mathcal{U} / \mathcal{K}$ is in the order of $10^{12}$ and therefore $\mathcal{K} \ll \mathcal{U}$, as characteristic for quasi-static loading. The kinetic energy during dynamic testing is 310 testing machine, where one specimen interface is at rest while the other is loaded by the cross-head displacement, both bar-specimen interfaces are in motion at an SHPB test. The specimen is therefore deformed by the relative displacement 
between the two interfaces and the kinetic energy in the specimen during SHPB

\section{Obtaining the Fracture Toughness Properties}

According to the analysis scheme (presented in Section 2 of the article), the size effect law $\sigma_{u}=\sigma_{u}(w)$ must be known to obtain the fracture toughness properties of the material. To find the relation between the ultimate nominal stress and the size of the specimen, Bažant and Planas [23] suggested different kinds of linear and bilogarithmic regression plots, all leading to very similar results for the R-curve. For the experimental results of the IM7-8552 DENC specimens (Section 4), a best fit was obtained for both QS and HR results by using the following linear regression [23]:

$$
\sigma_{u}^{-2}=m w+q
$$

in which $m$ and $q$ are the slope and the intercept of the linear curve fit, respectively. In Fig. 16, $\sigma_{u}^{-2}$ vs. $w$ and the corresponding linear fitting curves are plotted for both investigated strain rate regimes. The curve fitting parameters and the respective coefficient of determination $R^{2}$ are listed in Table 5.

[Figure 16 about here] 
All parameters of the analysis scheme apart from the size effect law can be calculated on basis of the material and specimen geometry data (Section 3). Fig. 17] shows the plot of the dimensionless correction function $\phi$ over the shape parameter $\alpha=a / w$ for the QS and HR material data sets.

With the defined size effect law, the R-curve of the laminate $R$ can be calculated by solving Eq. (8) for $w=w(\Delta a)$ and substituting this solution in Eq. (7). Finally, the R-curve of the $0^{\circ}$ plies $R_{0}$ is twice the value of $R$ for every $\Delta a$. The $R_{0}$-curves for both investigated strain rate regimes are presented in Fig. 18, showing that the compressive intralaminar fracture toughness of the $0^{\circ}$ plies under HR loading is considerably larger than that obtained under QS loading.

\section{[Figure 18 about here]}

For the chosen linear regression of the size effect law, the steady-state value of the fracture toughness $R_{s s}^{0}$ can be calculated as $[23]$ :

$$
R_{s s}^{0}=\lim _{w \rightarrow \infty} R_{0}=\frac{\sqrt{2(1+\rho)}}{E} \frac{\phi_{0}}{m}
$$

where $\phi_{0}=\left.\phi\right|_{\alpha=\alpha_{0}}$. The length of the fracture process zone $l_{f p z}$ in case of linear regression is [23]:

$$
l_{f p z}=\frac{f_{0}}{2 f_{0}^{\prime}} \frac{q}{m}
$$

where $f_{0}=\left.\sqrt{\phi}\right|_{\alpha=\alpha_{0}}$ and $f_{0}^{\prime}=\partial \sqrt{\phi} /\left.\partial \alpha\right|_{\alpha=\alpha_{0}}$. The values obtained for $R_{s s}^{0}$ and $l_{f p z}$ are summarized in Table 6. Table 6 also includes the corresponding coefficients of variation (CV), that are calculated according to Bažant and Planas [23] under additional consideration of the Young's modulus deviation.

[Table 6 about here] 
The steady-state value of the fracture toughness $R_{s s}^{0}$ under HR loading $\left(R_{s s}^{H R}=165.6 \mathrm{~kJ} / \mathrm{m}^{2}\right)$ is found to be $63 \%$ higher than the QS value $\left(R_{s s}^{Q S}=\right.$ are listed in Table 7

[Table 7 about here]

\section{Conclusions}

The presented work shows that the R-curve for the fiber compressive fail385 ure mode can be reliably measured for dynamic loading conditions, using the relations between the size effect law, the energy release rate and the R-curve.

It can be concluded, that the used double-edged notched specimens are well suitable for dynamic tests on a split-Hopkinson pressure bar setup. No significant difference could be found between the strain distributions, obtained from 


\section{Acknowledgements}

The authors would like to acknowledge Dr. Iman Taha and Christina Aust from Fraunhofer Institution for Casting, Composite and Processing Technology (IGCV) for providing the Photron FASTCAM SA-Z high speed camera. The 415

DIC, at quasi-static and high rate tests and the assumption of mode I could be verified for both investigated strain rate regimes. Furthermore, the DIC data enabled the calculation and comparison of the strain energy and kinetic energy terms, indicating that quasi-static fracture theory can be used without any significant error. In addition, stress equilibrium and a nearly constant strain rate of about $100 \mathrm{~s}^{-1}$ was achieved for all tested specimen sizes at the SHPB, ensuring a reliable determination of the size effect law.

For the investigated carbon-epoxy material IM7-8552, the R-curve for fiber compressive failure under high rate loading is increased compared to the quasistatic R-curve. The steady-state value of the fracture toughness under dynamic loading is $165.6 \mathrm{~kJ} / \mathrm{m}^{2}$ and therefore $63 \%$ higher than the quasi-static value of $101.6 \mathrm{~kJ} / \mathrm{m}^{2}$. The length of the fracture process zone also increases from $2.05 \mathrm{~mm}$ to $2.24 \mathrm{~mm}$ with increasing strain rate.

The results of the presented work contribute to a further understanding of the complex material response of polymer composite materials. It can be used to further enhance state-of-the art composite material models and therefore contributes to a more effective use of composite materials in primary automotive and aeronautical structures, where dynamic load scenarios must be considered during the design phase. With the presented results and earlier research published by the authors [33, 34, 42, a comprehensive dynamic material data set for the carbon-epoxy material IM7-8552 now exists.

presented research did not receive a specific grant from funding agencies in the public, commercial, or not-for-profit sectors. 


\section{Appendix A. Stress-strain curves}

The stress-strain curves of the specimen sizes A, B, C and D are shown in Fig. A.1, Fig. A.2, Fig. A.3 and Fig. A.4, respectively.

[Figure A.2 about here]

[Figure A.3 about here]

[Figure A.4 about here]

\section{Appendix B. Energy terms}

Fig. B.1, Fig. B.2 and Fig. B.3, show energy terms of specimen sizes A, B and C, respectively (for specimen size D see Fig. 15).

[Figure B.1 about here]

[Figure B.2 about here]

[Figure B.3 about here]

\section{References}

[1] Lapczyk I, Hurtado JA. Progressive damage modeling in fiber-reinforced materials. Composites: Part A 2007;38:2333-2341. doi $10.1016 / j$. compositesa.2007.01.017.

[2] Maimí P, Camanho PP, Mayugo JA, Dávila CG. A continuum damage model for composite laminates: Part II - Computational implementation

a and validation. Mechanics of Materials 2007;39:909-919. doi 10.1016/j. mechmat.2007.03.006 
[3] Camanho PP, Bessa MA, Catalanotti G, Vogler M, Rolfes R. Modeling the inelastic deformation and fracture of polymer composites Part II: Smeared crack model. Mechanics of Materials 2013;59:36-49. doi 10.1016/ j.mechmat.2012.12.001.

[4] Williams KV, Vaziri R, Poursartip A. A physically based continuum damage mechanics model for thin laminated composite structures. International Journal of Solids and Structures 2003;40:2267-2300. doi:110.1016/ S0020-7683(03) 00016-7.

[5] Forghani A, Zobeiry N, Poursartip A, Vaziri R. A structural modelling framework for prediction of damage development and failure of composite laminates. Journal of Composite Materials 2013;47:2553-2573. doi 10 . $1177 / 0021998312474044$.

[6] Dávila CG, Rose CA, Camanho PP. A procedure for superimposing linear cohesive laws to represent multiple damage mechanisms in the fracture of composites. International Journal of Fracture 2009;158:211-223. doi 10 . 1007/s10704-009-9366-z

[7] ASTM D5528-13, Standard test method for mode I interlaminar fracture toughness of unidirectional fiber-reinforced polymer matrix composites, ASTM International, West Conshohocken, PA. 2013. doi 10.1520/D5528.

[8] DIN EN 6033, Aerospace series - Carbon fibre reinforced plastics - Test method - Determination of interlaminar fracture toughness energy - Mode I - GIC; German and English version EN 6033:2015. 2015.

[9] DIN EN 6034, Aerospace series - Carbon fibre reinforced plastics - Test method - Determination of interlaminar fracture toughness energy - Mode II - G[IIC]; German and English version EN 6034:2015. 2015.

[10] Pinho ST, Robinson P, Iannucci L. Fracture toughness of the tensile and compressive fibre failure modes in laminated composites. Composites Sci- 
ence and Technology 2006;66:2069-2079. doi 10.1016/j.compscitech. 2005.12 .023

[11] Catalanotti G, Camanho PP, Xavier J, Dávila CG, Marques AT. Measurement of resistance curves in the longitudinal failure of composites using digital image correlation. Composites Science and Technology 2010;70:1986 1993. doi $10.1016 /$ j.compscitech.2010.07.022.

[12] Zobeiry N, Vaziri R, Poursartip A. Characterization of strain-softening behavior and failure mechanisms of composites under tension and compression. Composites: Part A 2015;68:29-41. doi 110.1016/S0020-7683(03) 00016-7.

[13] Laffan MJ, Pinho ST, Robinson P, Iannucci L, McMillan A. Measurement of the fracture toughness associated with mode I fibre compressive failure. In: 14th European Conference on Composite Materials, Budapest, Hungary; 2010.

[14] Soutis C, Curtis PT, Fleck NA. Compressive failure of notched carbon fibre composites. Proceedings: Mathematical and Physical Sciences $1993 ; 440: 241-256$.

[15] Catalanotti G, Xavier J, Camanho PP. Measurement of the compressive crack resistance curve of composites using the size effect law. Composites: Part A 2014;56:300-307. doi:10.1016/j.compositesa.2013.10.017.

[16] Catalanotti G, Arteiro A, Hayati M, Camanho PP. Determination of the mode I crack resistance curve of polymer composites using the sizeeffect law. Engineering Fracture Mechanics 2014;118:49-65. doi 10.1016/ j.engfracmech.2013.10.021.

[17] Catalanotti G, Xavier J. Measurement of the mode II intralaminar fracture toughness and R-curve of polymer composites using a modified Iosipescu specimen and the size effect law. Engineering Fracture Mechanics 2015;138:202-214. doi:10.1016/j.engfracmech.2015.03.005. 
[18] Pinto RF, Catalanotti G, Camanho PP. Measuring the intralaminar crack resistance curve of fibre reinforced composites at extreme temperatures. Composites: Part A 2016;91:145-155. doi 10.1016/j.compositesa.2016. 10.004

[19] Sierakowski RL. Strain rate effects in composites. Applied Mechanics Reviews 1997;50:741-761. doi $10.1115 / 1.3101860$.

[20] Jacob GC, Starbuck JM, Fellers JF, Simunovic S, Boeman RG. Strain rate effects on the mechanical properties of polymer composite materials. Journal of Applied Polymer Science 2004;94:296-301. doi:10.1002/app. 20901 .

[21] Jacob GC, Starbuck JM, Fellers JF, Simunovic S, Boeman RG. The effect of loading rate on the fracture toughness of fiber reinforced polymer composites. Journal of Applied Polymer Science 2005;96:899-904. doi $10.1002 /$ app. 21535 .

[22] McCarroll C. High rate fracture toughness measurements of laminated composites. Ph.D. thesis; Imperial College London; 2011.

[23] Bažant ZP, Planas J. Fracture and size effect in concrete and other quasibrittle materials. CRC Press LLC, Boca Raton, Florida, USA; 1998.

[24] Laffan MJ, Pinho ST, Robinson P, McMillan A. Translaminar fracture toughness testing of composites: a review. Polymer Testing 2012;31:481489. doi $10.1016 / j \cdot$ polymertesting. 2012.01.002.

[25] Jiang F, Vecchio KS. Hopkinson bar loaded fracture experimental technique: A critical review of dynamic fracture toughness tests. Applied Mechanics Reviews 2009;62:1-39. doi 10.1115/1.3124647.

[26] Suo Z, Bao G, Fan B, Wang TC. Orthotropy rescaling and implications for fracture in composites. International Journal of Solids and Structures 1990;28:235-248. 
[34] Koerber H, Camanho PP. High strain rate characterisation of unidirectional carbon-epoxy IM7-8552 in longitudinal compression. Composites Part A 2011;42:462-470. doi $10.1016 /$ j.compositesa.2011.01.002.

${ }_{545}[35]$ Nemat-Nasser S, Isaacs JB, Starrett JE. Hopkinson techniques for dynamic recovery experiments. Proceedings: Mathematical and Physical Sciences 1991;435:371-391. 
[36] Koerber H, Xavier J, Camanho PP, Essa YE, de la Escalera FM. High strain rate behaviour of 5 -harness-satin weave fabric carbonepoxy composite under compression and combined compressionshear loading. International Journal of Solids and Structures 2015;54:172-182. doi:10.1016/j. ijsolstr.2014.10.018.

[37] Kolsky H. An investigation of the mechanical properties of materials at very high rates of loading. Proc Phys Soc London 1949;Sect. B. 62 (IIB):676-700.

[38] G. T. Gray III . Classic split-Hopkinson pressure bar testing. In: ASM handbook mechanical testing and evaluation; vol. 8. ASM International Ohio USA; 2000, pp. 462-476.

[39] Gama BA, Gillespie JW. Numerical hopkinson bar analysis: uni-axial stress and planar bar-specimen interface conditions by design. Tech. Rep. ARL-CR-553; Army Research Laboratory, USA; 2004.

[40] Mase GT, Smelser RE, Mase GE. Continuum mechanics for engineers. CRC Press LLC, Boca Raton, Florida, USA; 2010.

[41] S. Nemat-Nasser . Introduction to high strain rate testing. In: ASM handbook mechanical testing and evaluation; vol. 8. ASM International Ohio USA; 2000.

[42] Kuhn P, Ploeckl M, Koerber H. Experimental investigation of the failure envelope of unidirectional carbon-epoxy composite under high strain rate transverse and off-axis tensile loading. In: 11th International Conference on the Mechanical and Physical Behaviour of Materials under Dynamic Loading, Lugano, Switzerland, 2015; vol. 94. 2015, p. 01040 1-6. doi 10. 1051/epjconf/20159401040. 


\section{Figures}

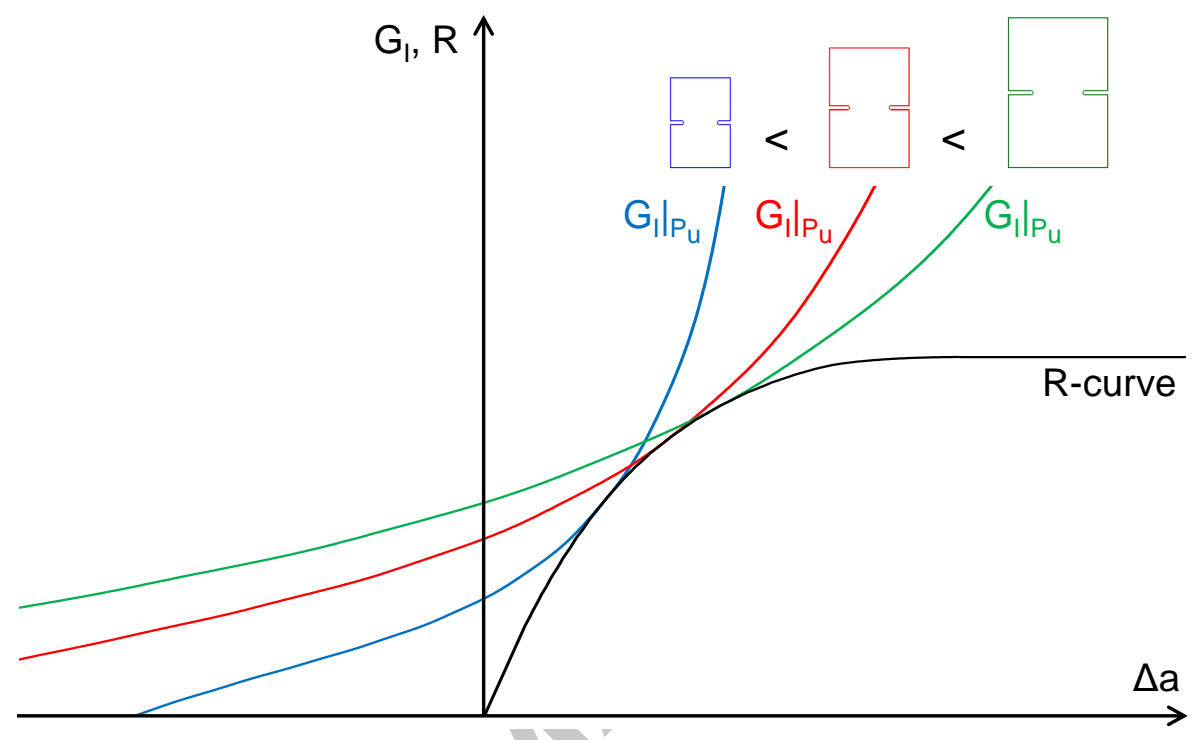

Figure 1: Crack driving force curves $G_{I}$ for different specimen sizes at respective peak load $P_{u}$ and R-curve. 


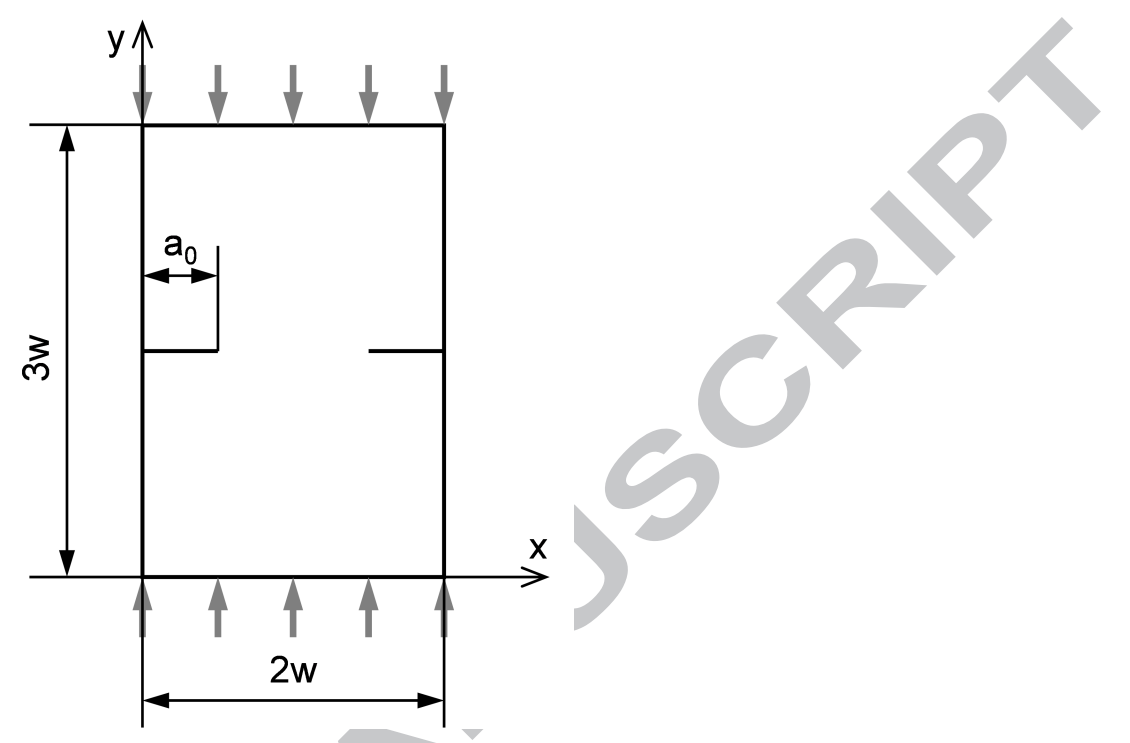

Figure 2: Double edge notched compression (DENC) specimen. 


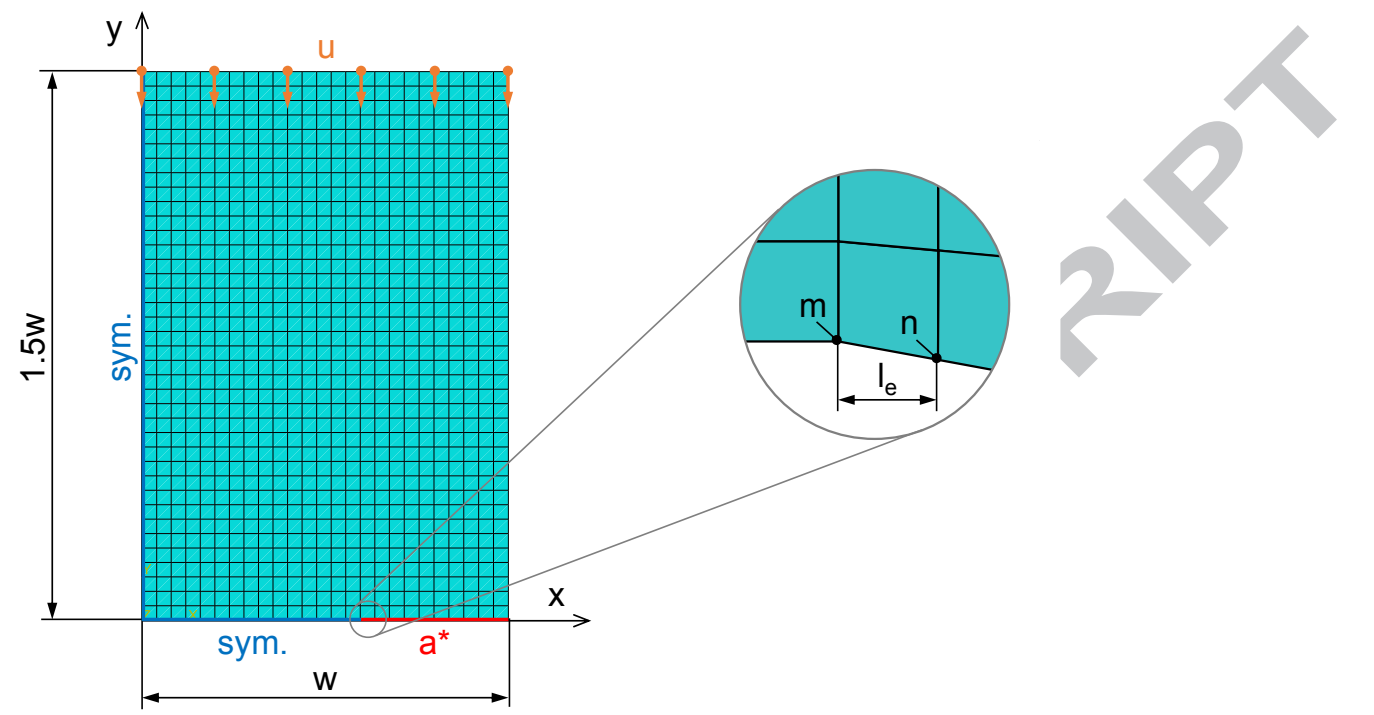

Figure 3: Finite element model used for application of VCCT. 


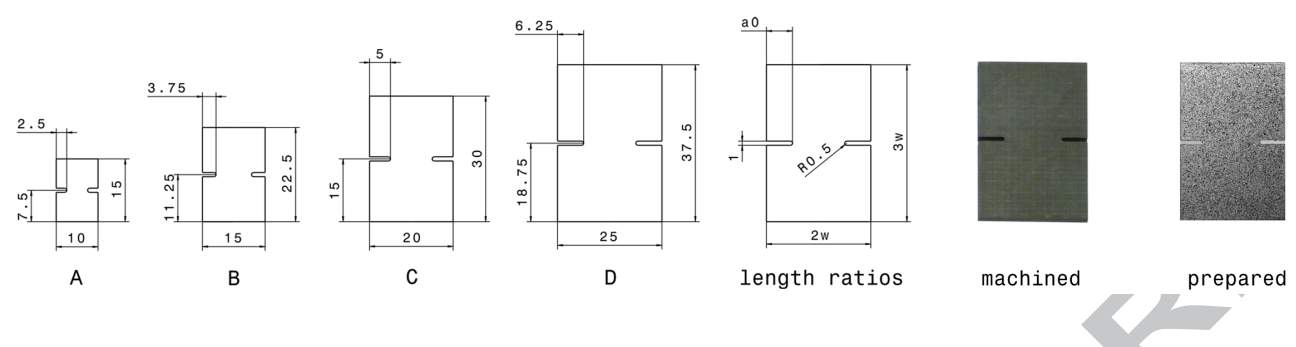

Figure 4: Used specimen sizes (dimensions in $\mathrm{mm}$ ), machined and prepared specimen for DIC measurement (size D). 


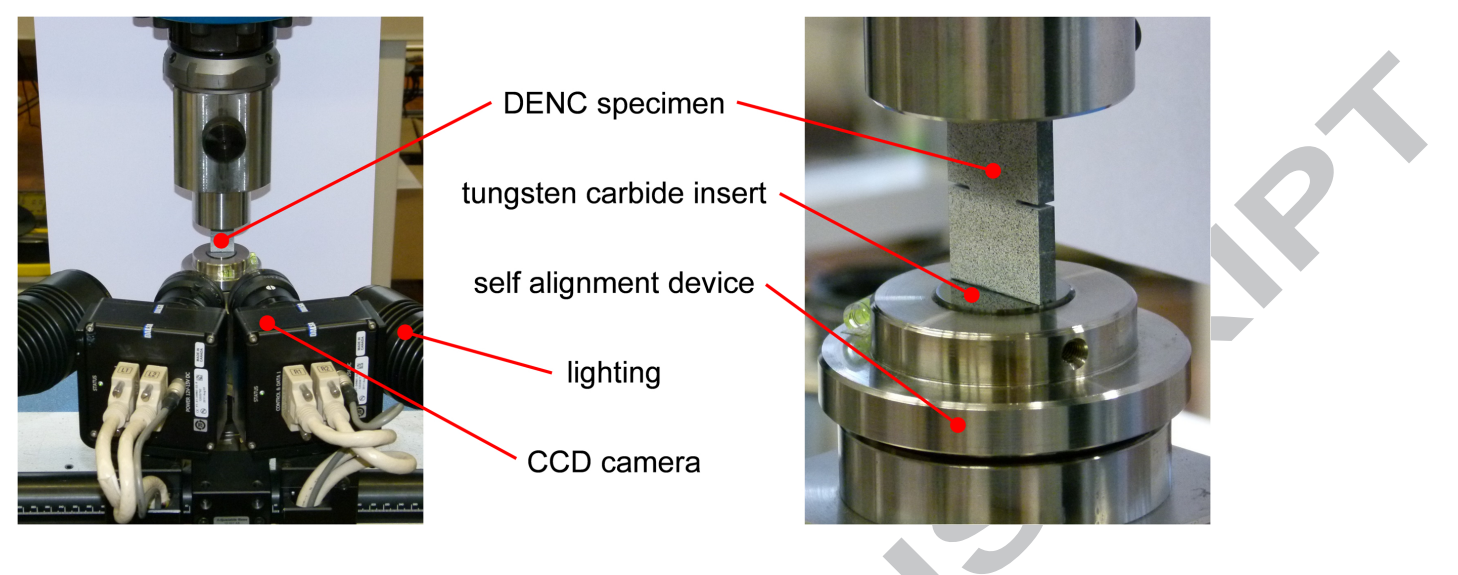

Figure 5: Compression setup for quasi-static tests. 


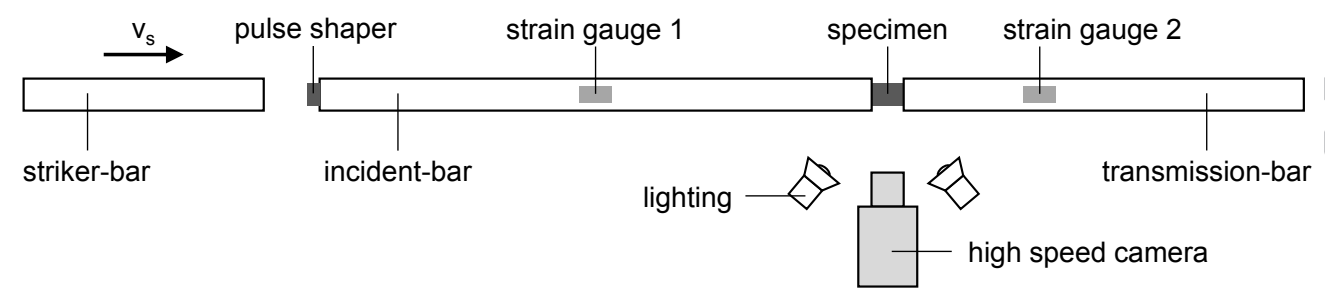

Figure 6: Split-Hopkinson pressure bar (SHPB) setup for dynamic tests. 


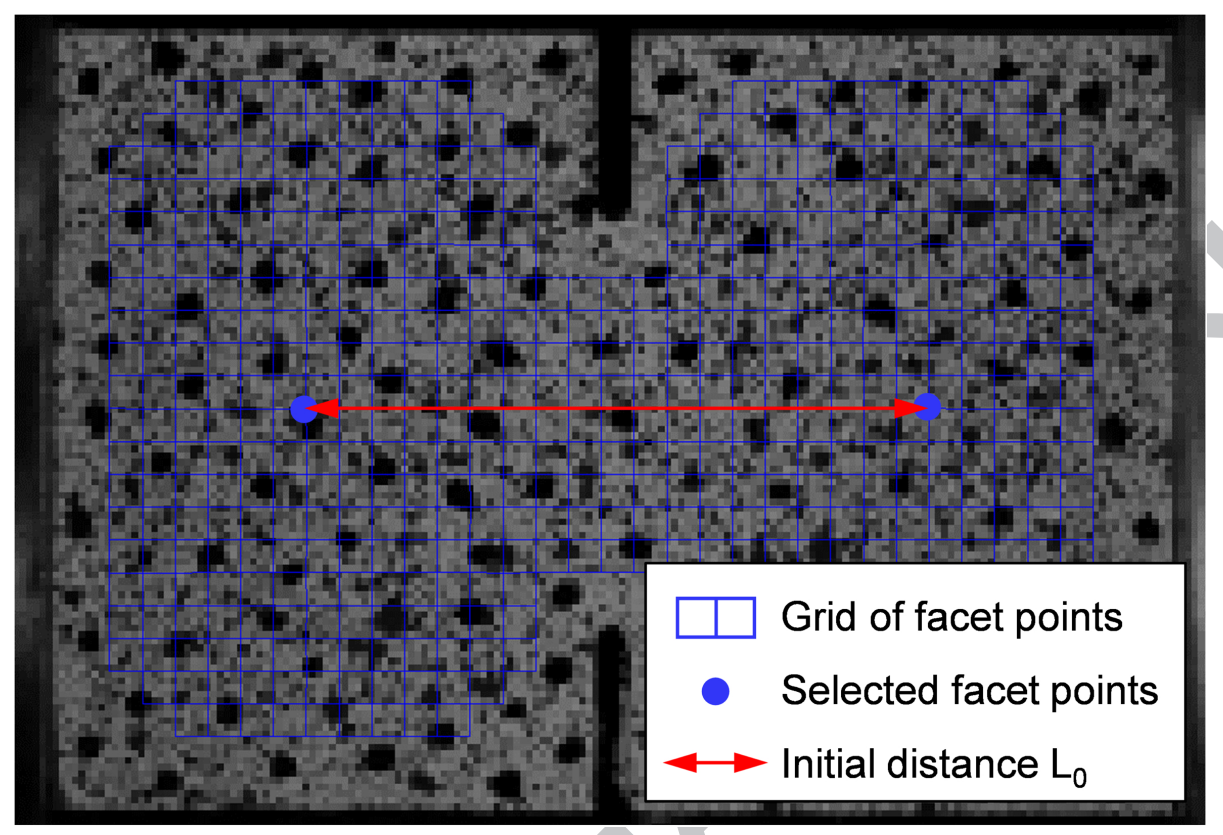

Figure 7: Aramis analysis parameters on DENC-specimen (specimen size D). 


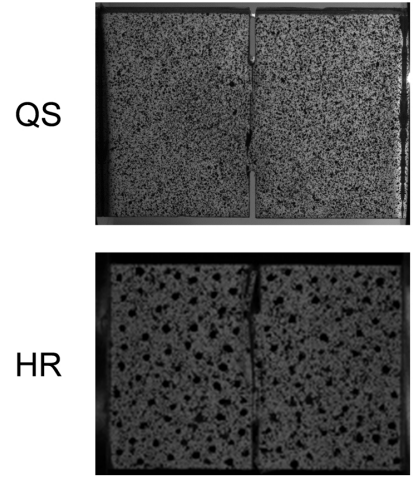

(a) failure

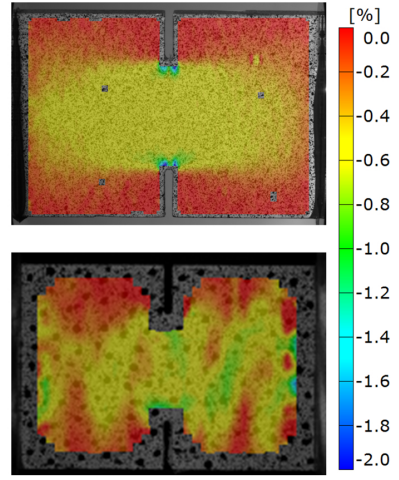

(b) axial strain

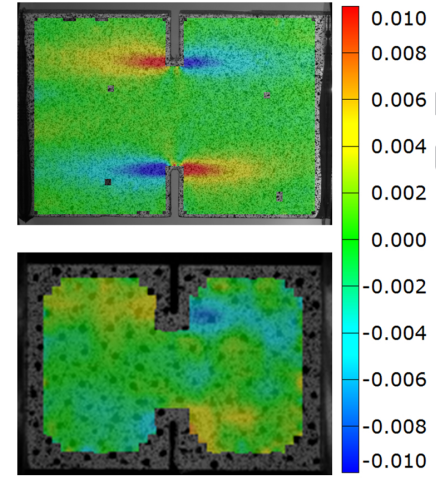

(c) shear strain

Figure 8: Failed specimens (a) and strain fields at same axial strain level $(\epsilon \approx 0.5 \%)(\mathrm{b}, \mathrm{c})$ under QS and HR loading (specimen size C, QS images are rotated 90 counterclockwise). 


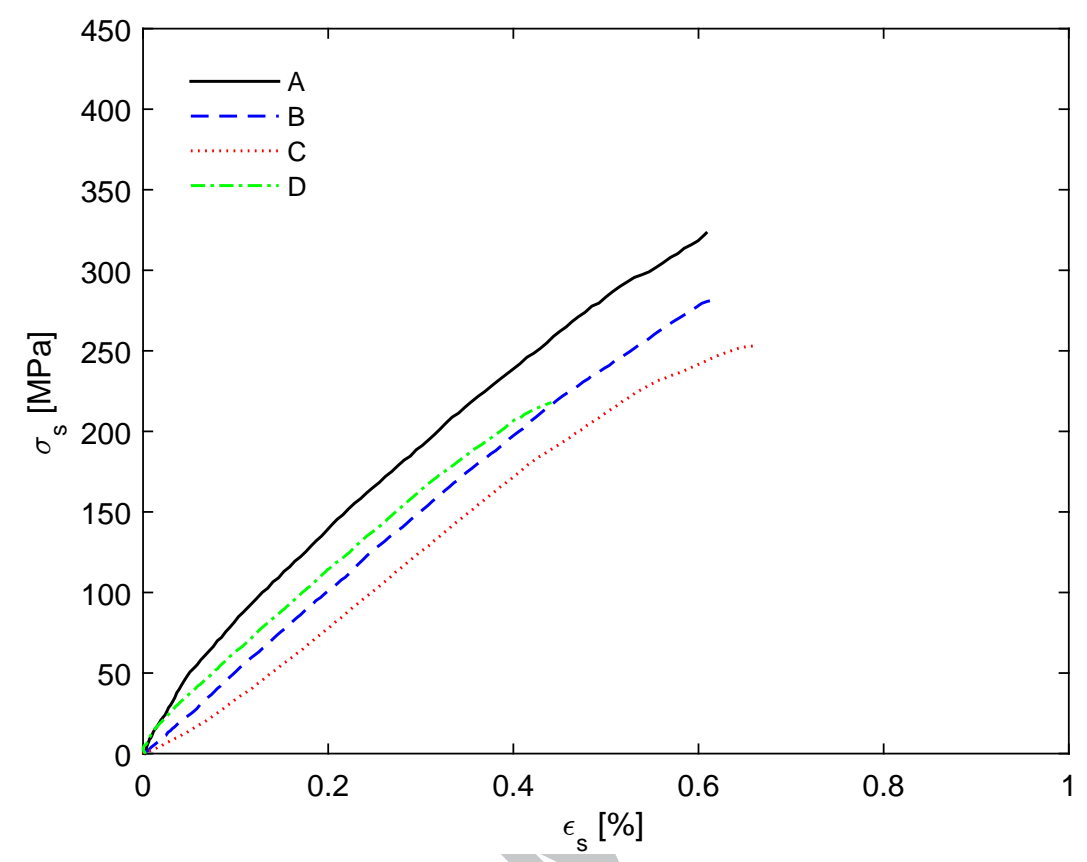

Figure 9: Stress-strain response for QS loading. 


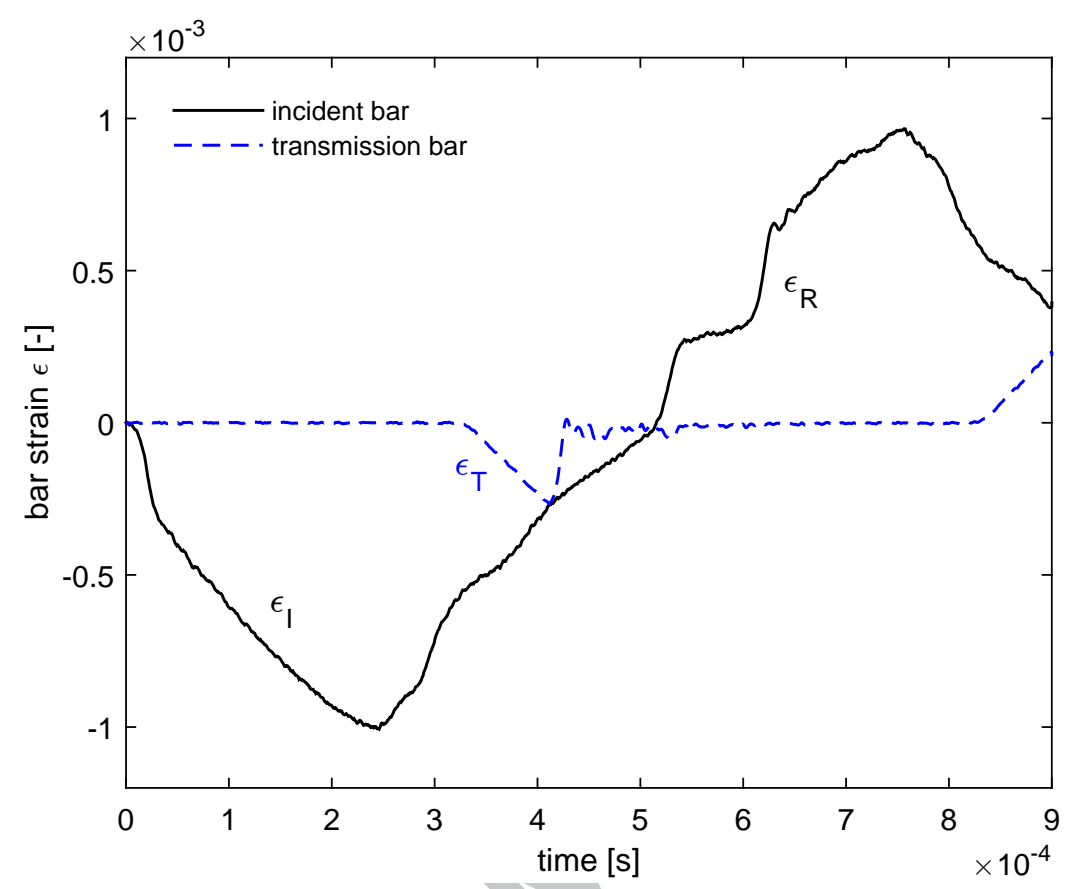

Figure 10: Example of a bar strain wave group of an SHPB test (specimen size C). 


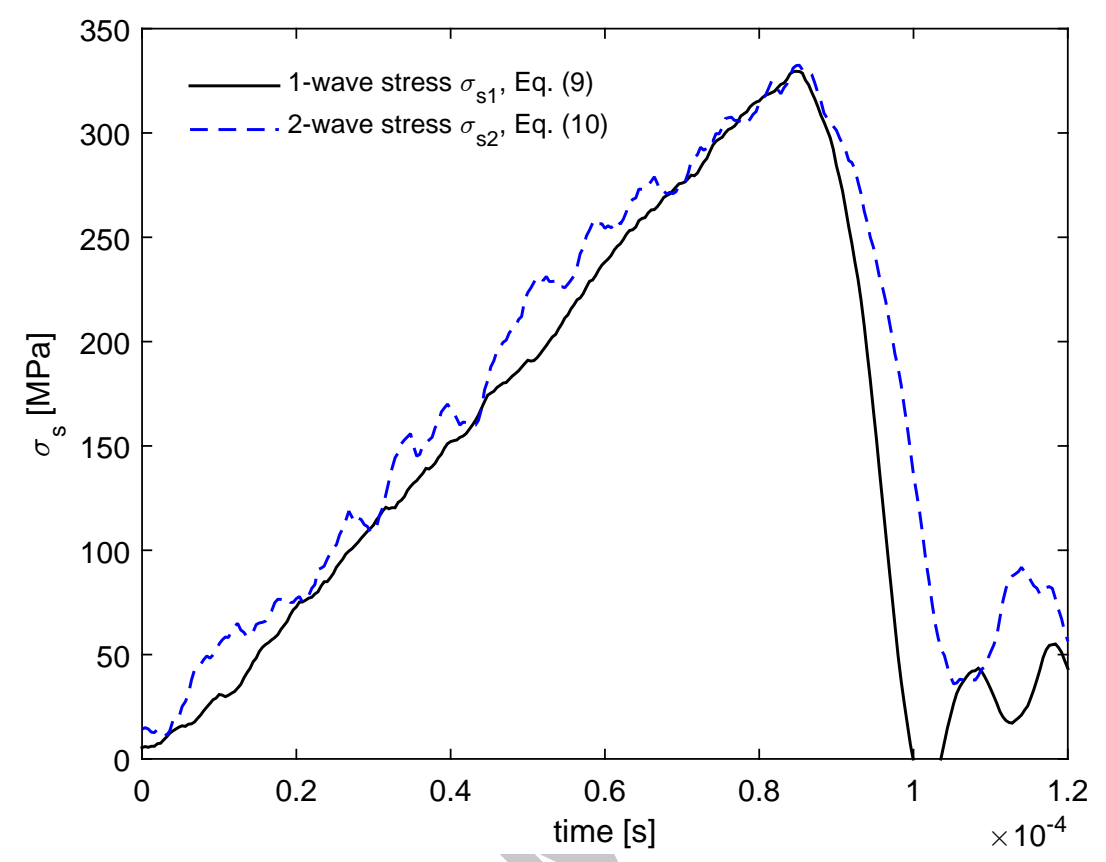

Figure 11: Example of a dynamic stress equilibrium check (specimen size C). 


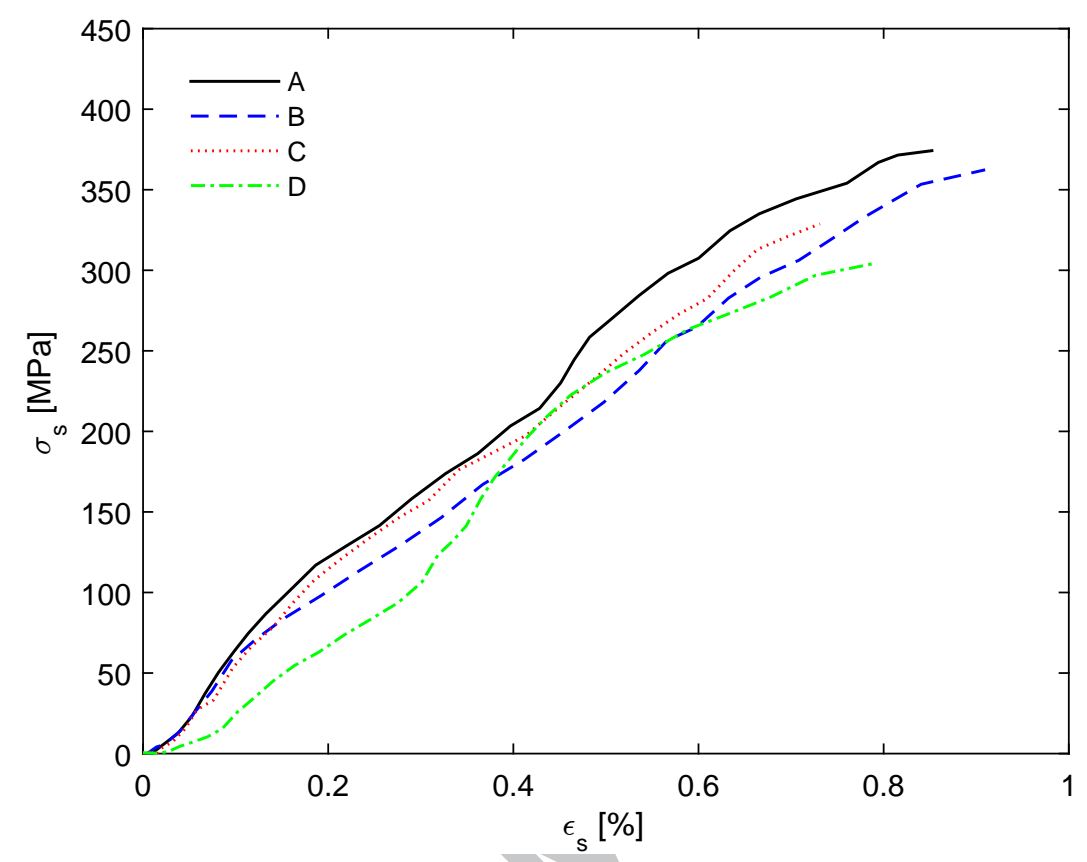

Figure 12: Stress-strain response for HR loading. 


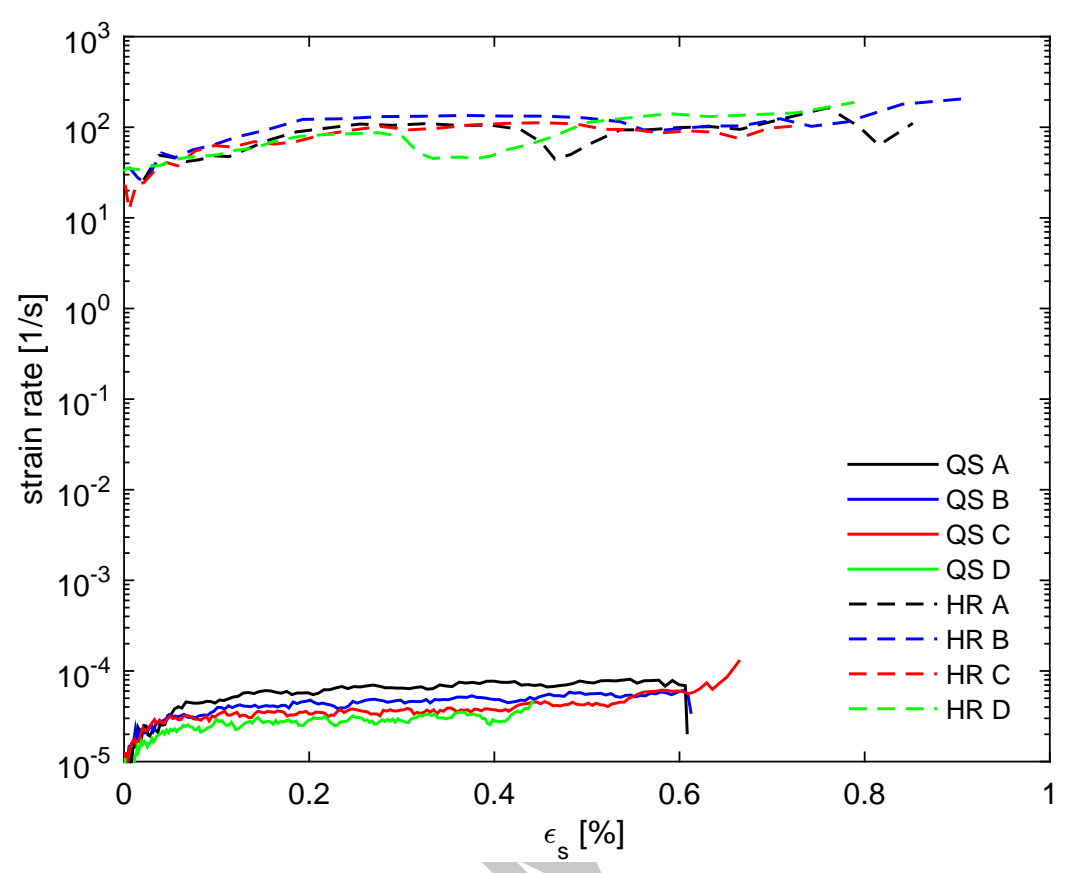

Figure 13: Specimen strain rate curves for QS and HR loading. 


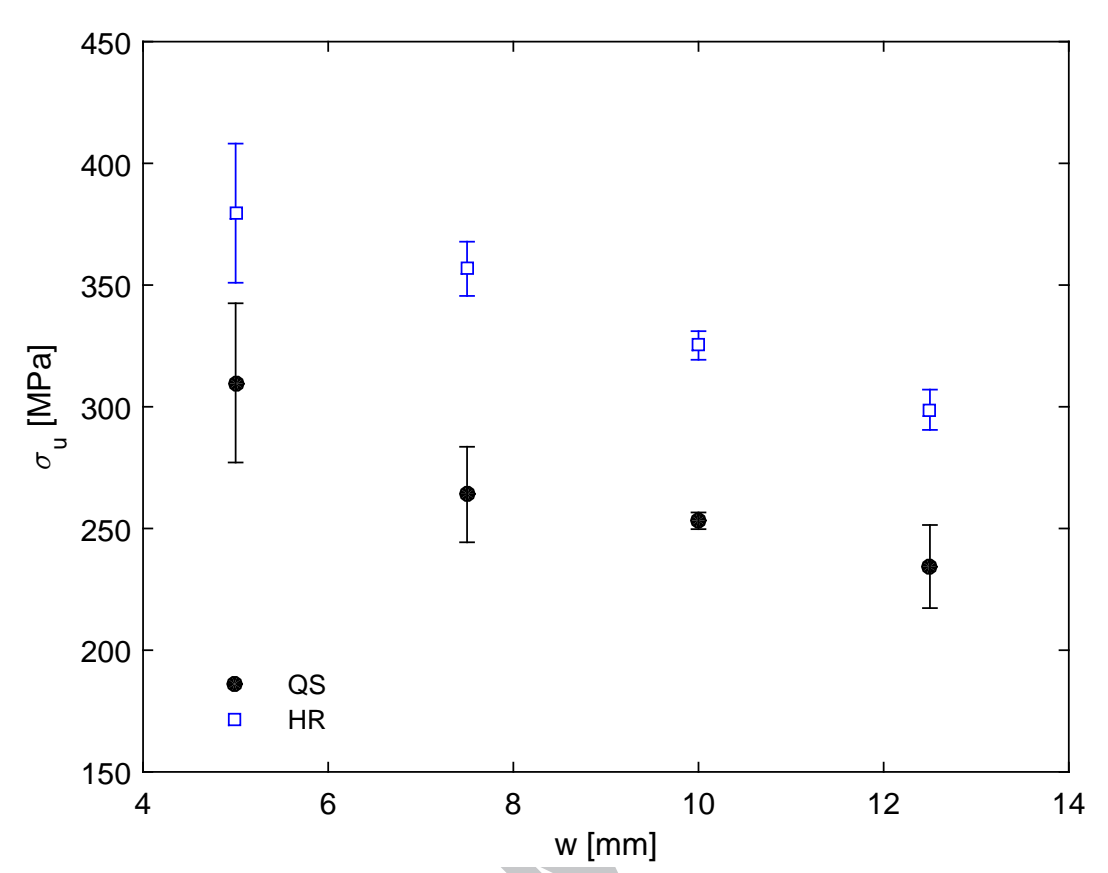

Figure 14: Ultimate stress $\sigma_{u}$ vs. specimen size $w$ for QS and HR loading. 


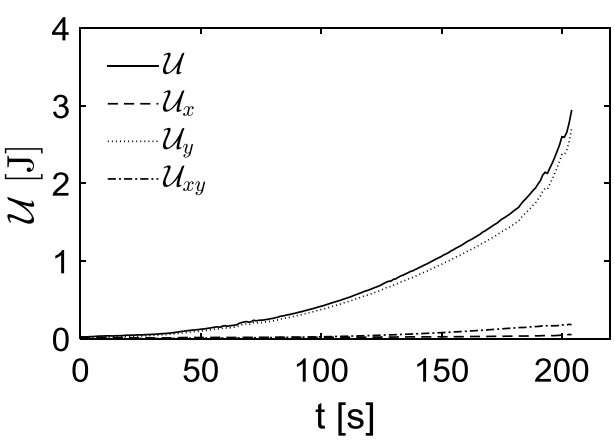

(a) QS strain energy

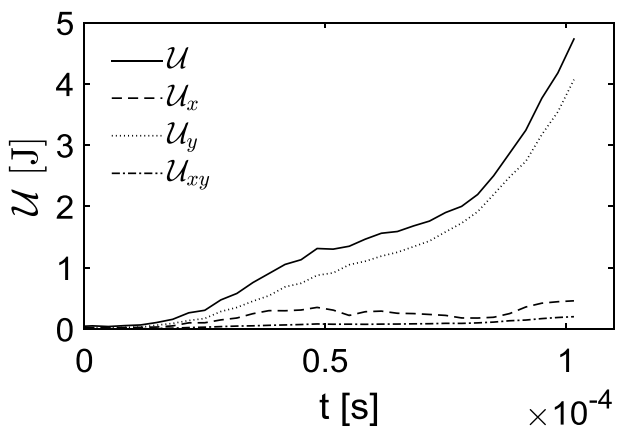

(c) HR strain energy

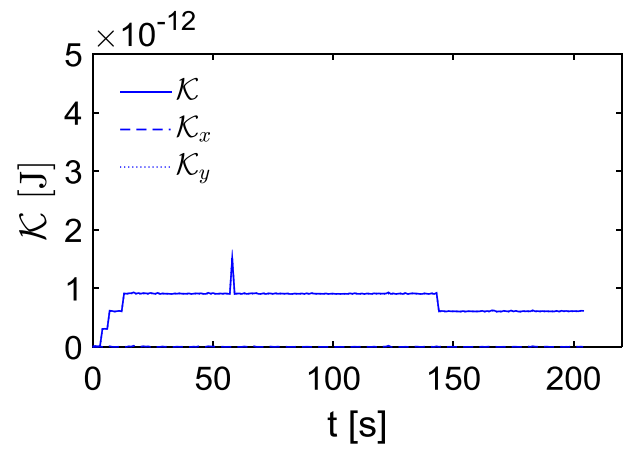

(b) QS kinetic energy

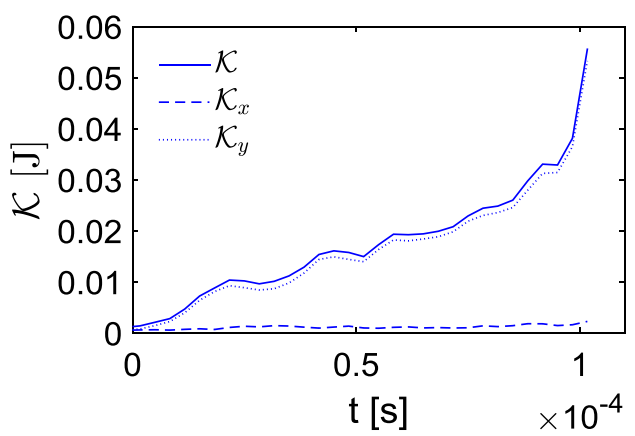

(d) HR kinetic energy

Figure 15: Example of strain and kinetic energy terms for QS (a, b) and HR (c, d) loading (specimen size D). 


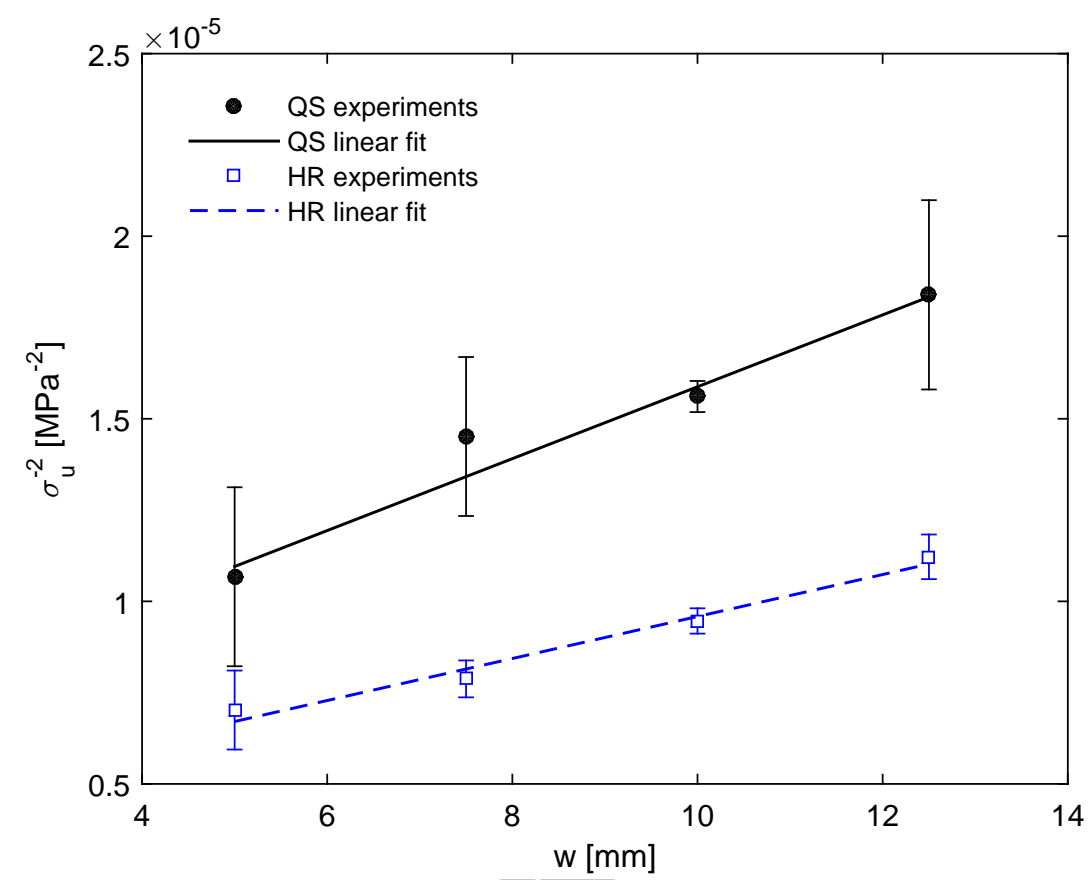

Figure 16: $\sigma_{u}^{-2}$ vs. $w$ and linear fitting for QS and HR loading. 


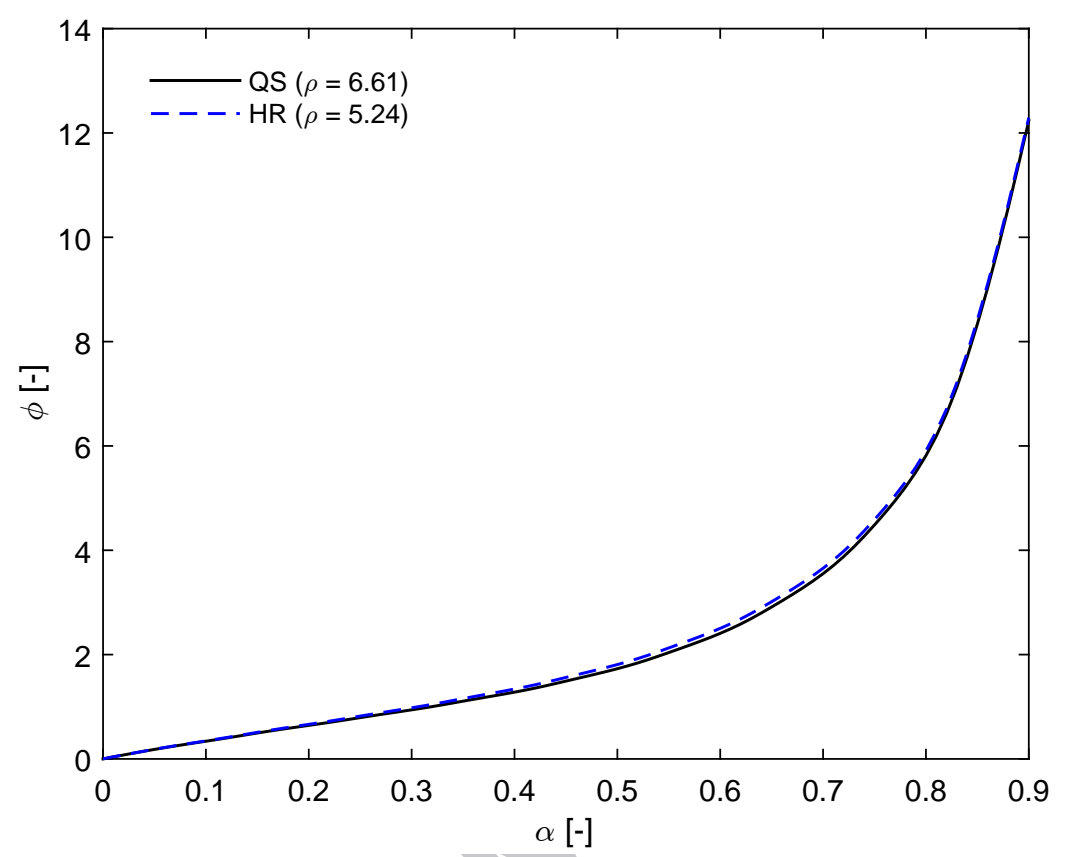

Figure 17: Correction function $\phi$ vs. specimen size $w$ for QS and HR loading. 


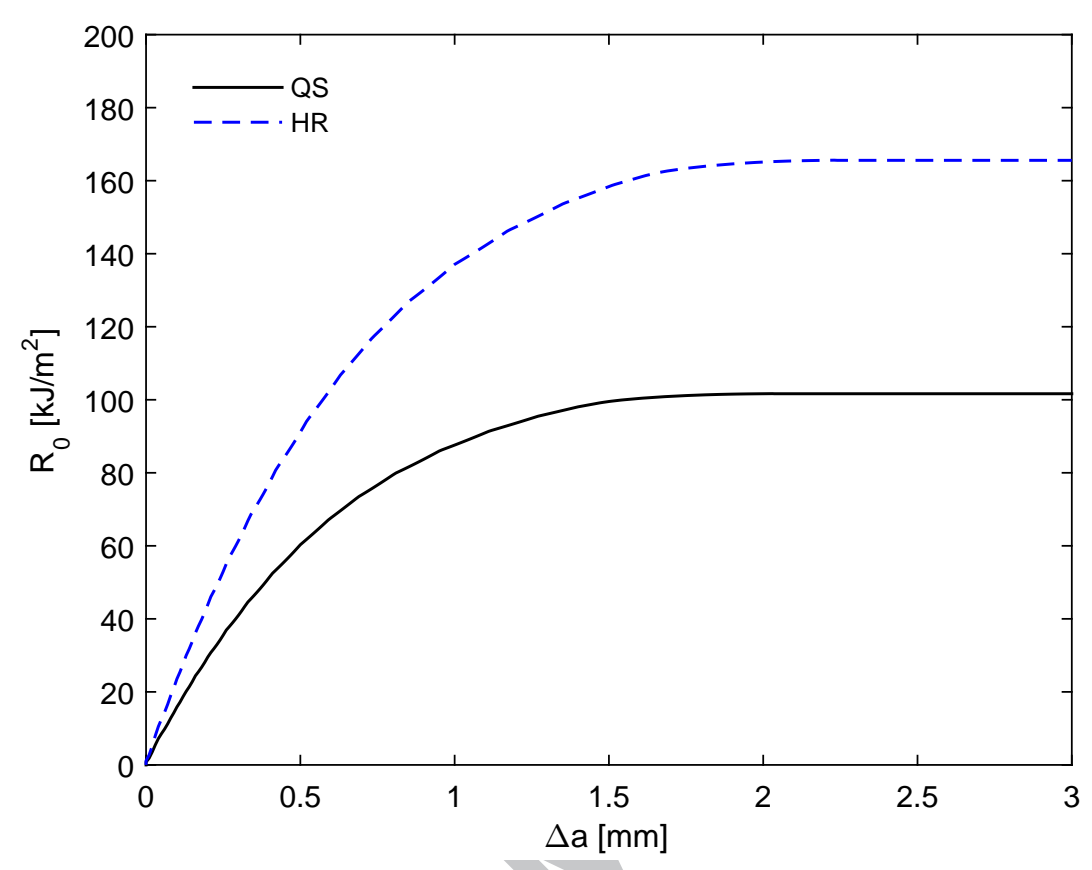

Figure 18: Compressive R-curve of IM7-8552 for QS and HR loading. 


\section{Figures Appendix A}

(a)

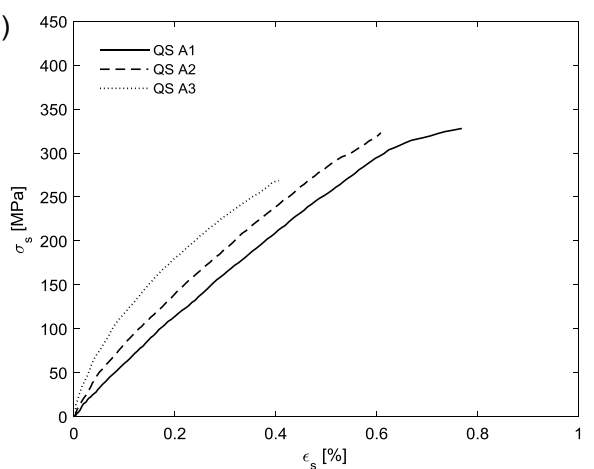

(b)

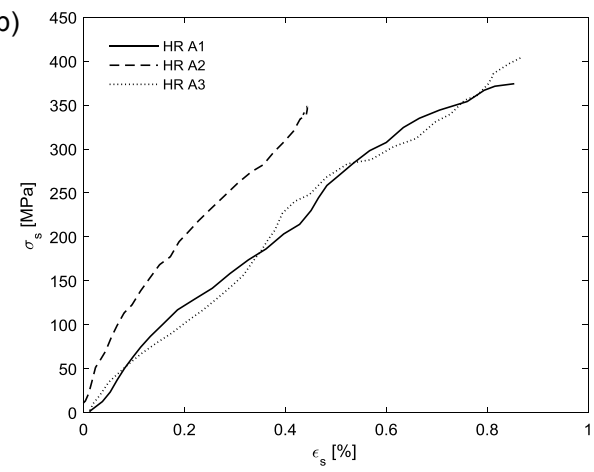

Figure A.1: Stress-strain responses of specimen size A for QS (a) and HR (b) loading. 
(a)

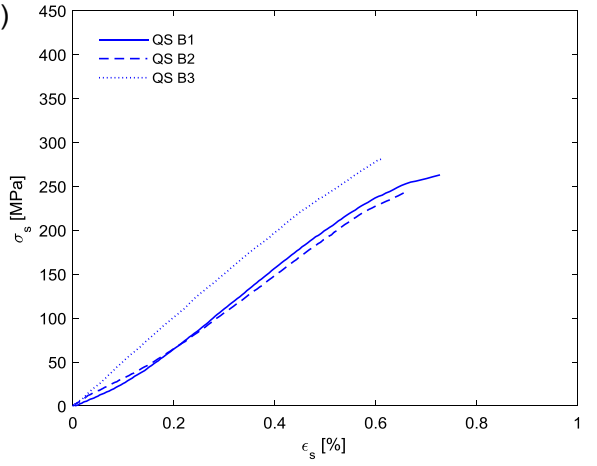

(b)

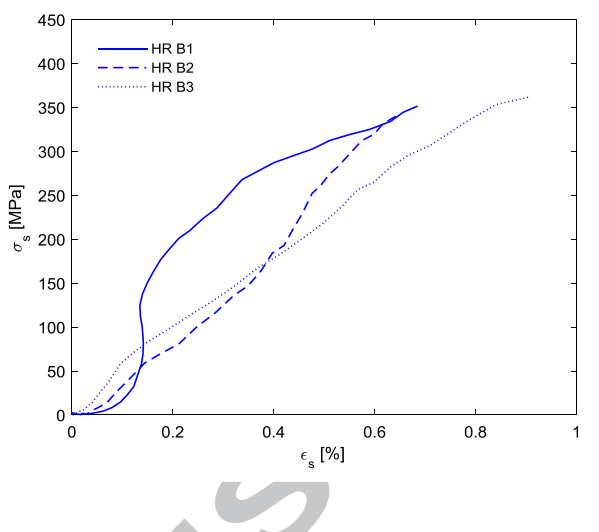

Figure A.2: Stress-strain responses of specimen size B for QS (a) and HR (b) loading. 
(a)

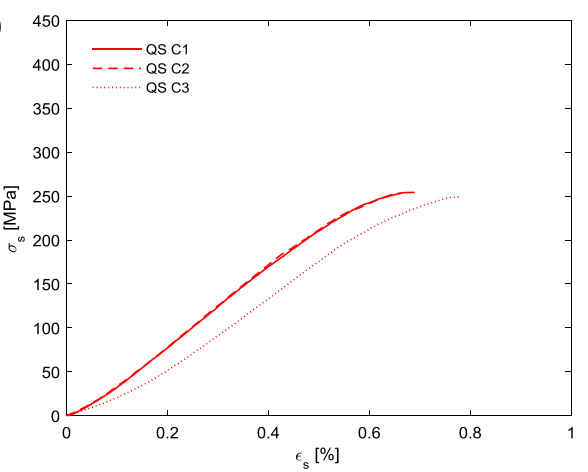

(b)

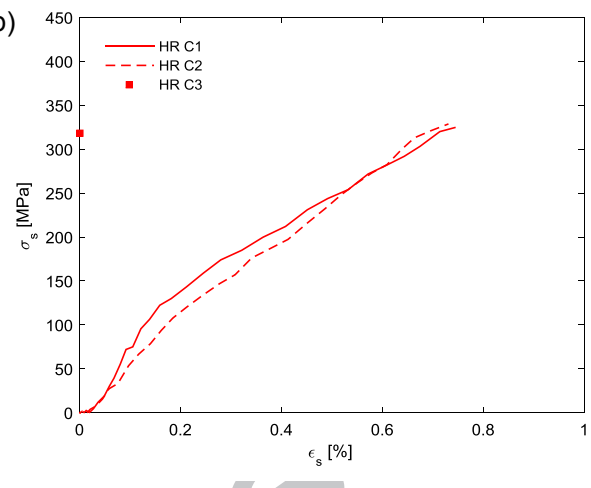

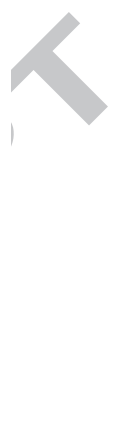

Figure A.3: Stress-strain responses of specimen size C for QS (a) and HR (b) loading. 
(a)

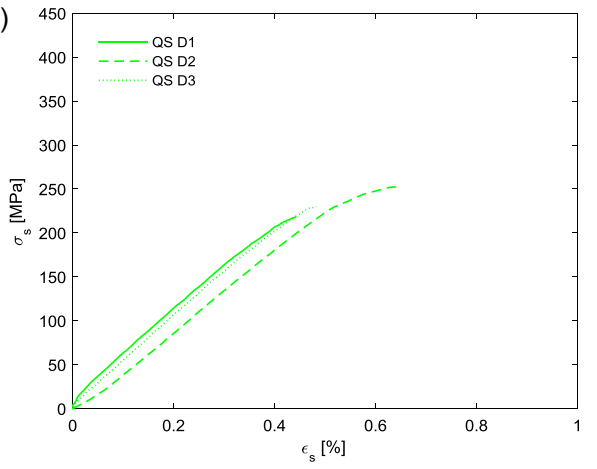

(b)

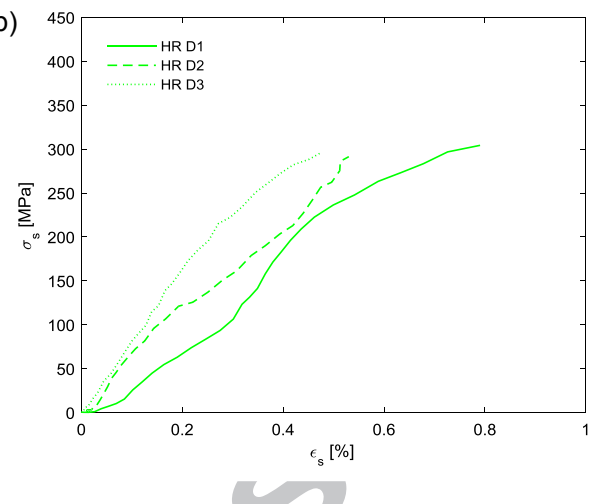

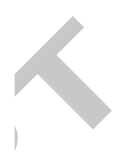

Figure A.4: Stress-strain responses of specimen size D for QS (a) and HR (b) loading. 
${ }_{575}$ Figures Appendix B

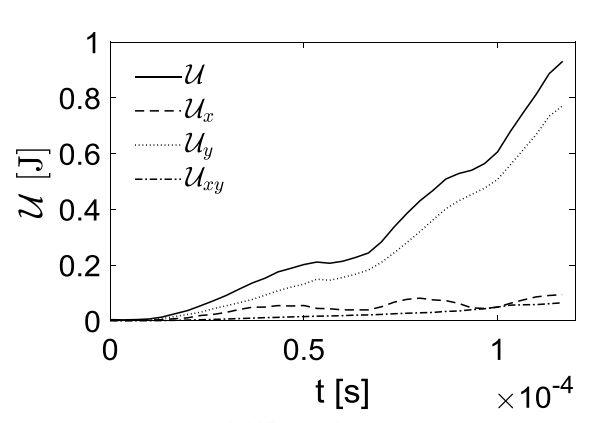

(a) HR strain energy

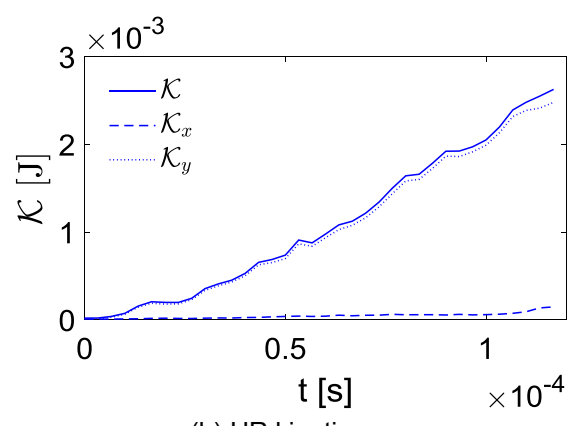

(b) HR kinetic energy

Figure B.1: Example of strain (a) and kinetic (b) energy terms for HR loading of specimen size A. 


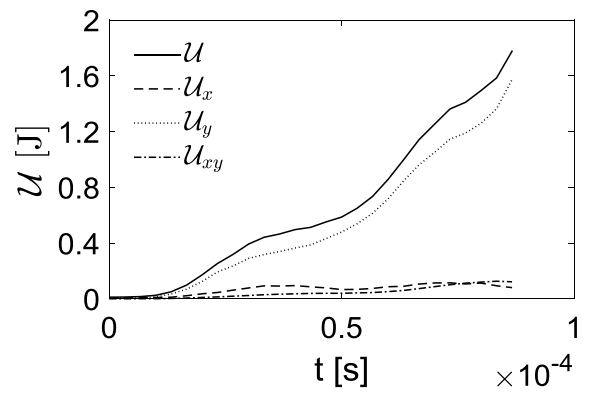

(a) HR strain energy

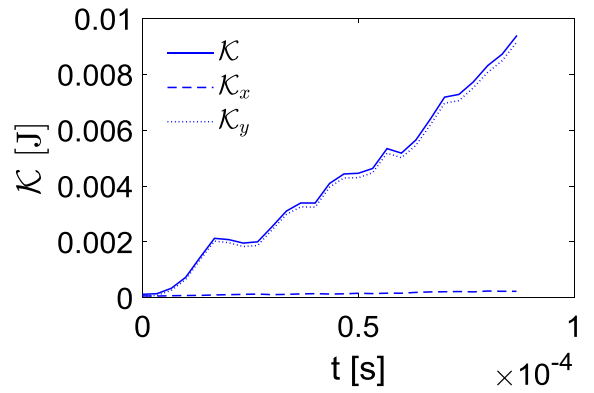

(b) HR kinetic energy

Figure B.2: Example of strain (a) and kinetic (b) energy terms for HR loading of specimen size B. 


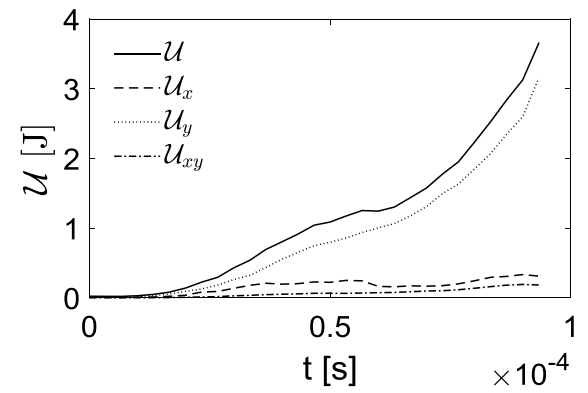

(a) HR strain energy

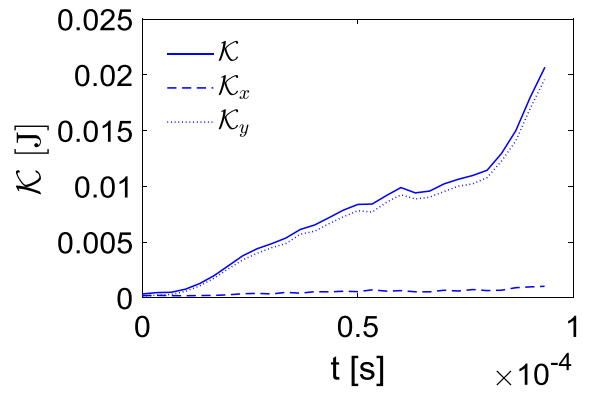

(b) HR kinetic energy

Figure B.3: Example of strain (a) and kinetic (b) energy terms for HR loading of specimen size C. 


\section{Tables}

Table 1: Elastic properties of the laminate.

\begin{tabular}{ccccc}
\hline Strain rate regime & $\begin{array}{c}E \\
{[\mathrm{MPa}]}\end{array}$ & $\begin{array}{c}G_{x y} \\
{[\mathrm{MPa}]}\end{array}$ & $\begin{array}{c}\nu_{x y} \\
{[-]}\end{array}$ & $\begin{array}{c}\rho \\
{[-]}\end{array}$ \\
\hline QS & 67,449 & 5,068 & 0.042 & 6.61 \\
$\mathrm{HR}$ & 67,126 & 6,345 & 0.048 & 5.24 \\
\hline
\end{tabular}
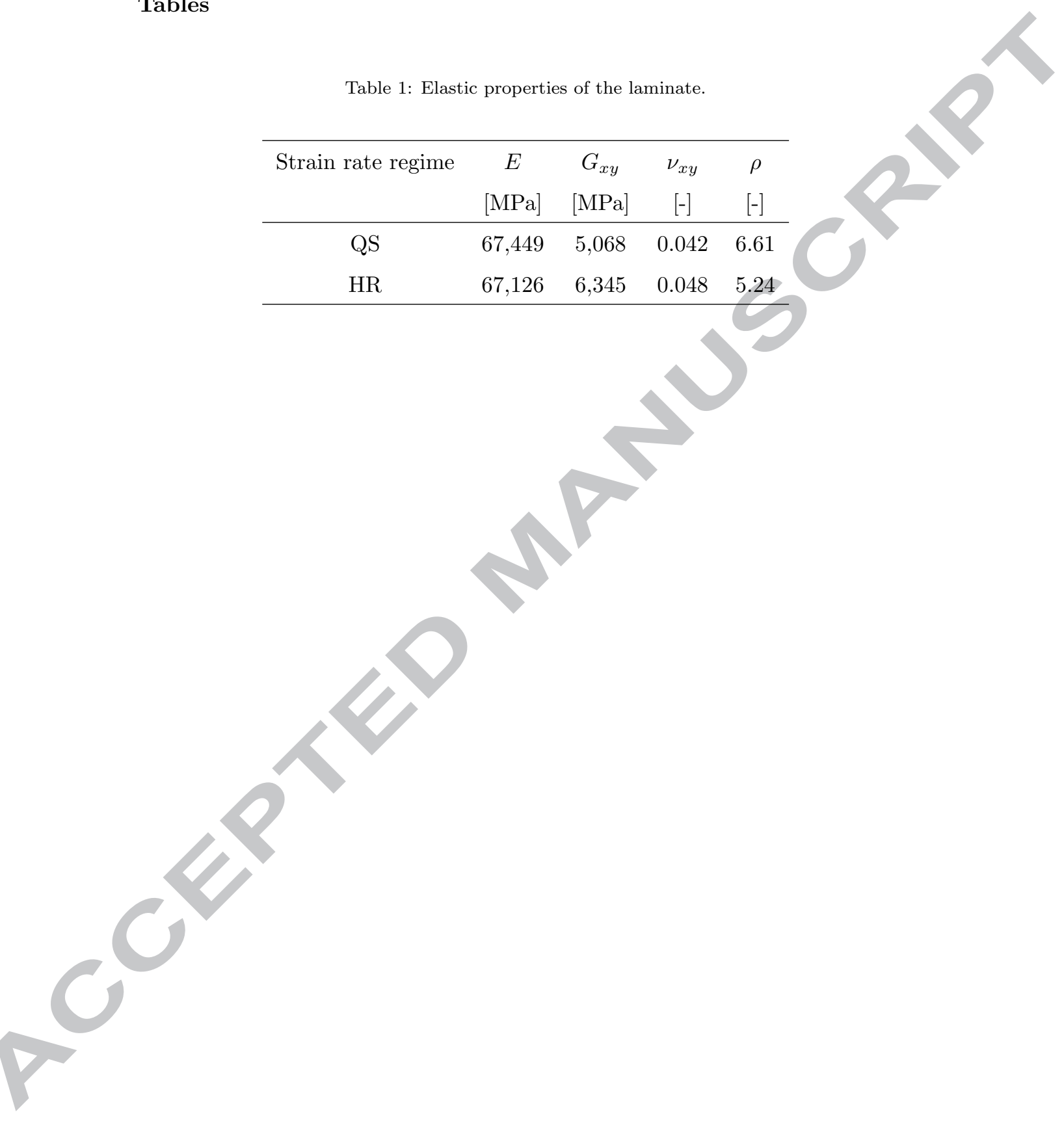
Table 2: Split-Hopkinson pressure bar parameters.

\begin{tabular}{cccccc}
\hline Specimen type & $\begin{array}{c}w \\
{[\mathrm{~mm}]}\end{array}$ & $\begin{array}{c}d_{b} \\
{[\mathrm{~mm}]}\end{array}$ & $\begin{array}{c}v_{s} \\
{[\mathrm{~m} / \mathrm{s}]}\end{array}$ & \multicolumn{2}{c}{$\begin{array}{c}\text { Pulse Shaper dimensions } \\
{[\mathrm{mm}]}\end{array}$} \\
\cline { 4 - 6 } & & & & $d_{P S}$ & $t_{P S}$ \\
\hline $\mathrm{A}$ & 5 & 16 & 8.6 & 6 & 1.5 \\
$\mathrm{~B}$ & 7.5 & 18 & 9.4 & 8 & 1.5 \\
$\mathrm{C}$ & 10 & 18 & 11.0 & 10 & 2.0 \\
$\mathrm{D}$ & 12.5 & 25 & 12.2 & 10 & 2.0 \\
\hline
\end{tabular}


Table 3: ARAMIS analysis parameters.

\begin{tabular}{cccccc}
\hline Parameter & QS & \multicolumn{5}{c}{ HR } \\
\cline { 3 - 6 } & & A & B & C & D \\
\hline Conversion factor $[\mathrm{mm} /$ pixel] & 0.021 & 0.084 & 0.127 & 0.170 & 0.224 \\
Facet size $\left[\mathrm{pixel}^{2}\right]$ & $17 \times 17$ & & $10 \times 10$ \\
Facet step $\left[\mathrm{pixel}^{2}\right]$ & $15 \times 15$ & & $5 \times 5$ & \\
Computation size $\left[\mathrm{facets}^{2}\right]$ & $5 \times 5$ & & $5 \times 5$ & \\
\hline
\end{tabular}


Table 4: Summary of the experimental results

\begin{tabular}{llcccc}
\hline & & $\mathrm{A}$ & $\mathrm{B}$ & $\mathrm{C}$ & $\mathrm{D}$ \\
\hline \multirow{2}{*}{$\mathrm{QS}$} & $\mathrm{w}[\mathrm{mm}]$ & 5 & 7.5 & 10 & 12.5 \\
& $\sigma_{u}[\mathrm{MPa}]$ & 310 & 264 & 253 & 234 \\
& $\mathrm{STDV}\left(\sigma_{u}\right)[\mathrm{MPa}]$ & 33 & 20 & 3 & 17 \\
$\mathrm{HR}$ & $\sigma_{u}[\mathrm{MPa}]$ & 380 & 357 & 325 & 299 \\
& $\mathrm{STDV}\left(\sigma_{u}\right)[\mathrm{MPa}]$ & 29 & 11 & 6 & 8 \\
\hline
\end{tabular}

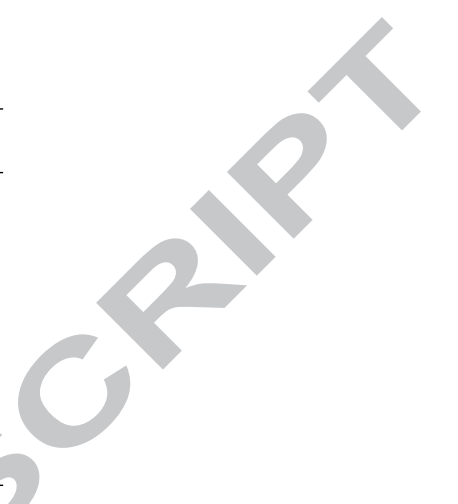


Table 5: Linear curve fitting parameters.

\begin{tabular}{cccc}
\hline Strain rate regime & $\begin{array}{c}m \\
{\left[\mathrm{MPa}^{-2} \mathrm{~mm}^{-1}\right]}\end{array}$ & $\begin{array}{c}R^{2} \\
{\left[\mathrm{MPa}^{-2}\right]}\end{array}$ & \begin{tabular}{c}
{$[-]$} \\
\hline QS
\end{tabular} \\
\hline HR & $5.84 \times 10^{-7}$ & $6.03 \times 10^{-6}$ & 0.960 \\
\hline
\end{tabular}

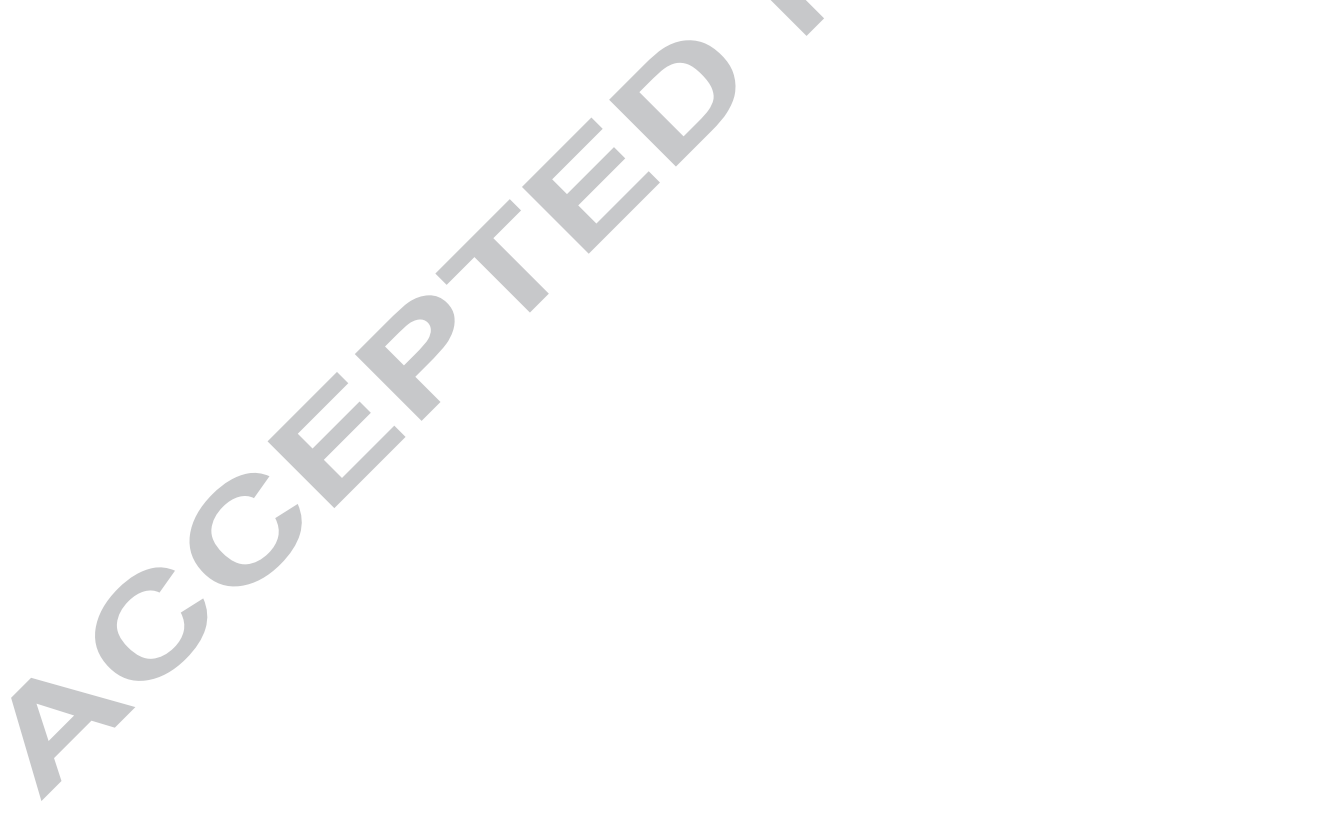


Table 6: Summary of the fracture toughness properties.

\begin{tabular}{ccc}
\hline Strain rate regime & $\begin{array}{c}R_{s s}^{0} \\
{\left[\mathrm{~kJ} / \mathrm{m}^{2}\right]}\end{array}$ & $\begin{array}{c}l_{f p z} \\
{[\mathrm{~mm}]}\end{array}$ \\
\hline $\mathrm{QS}$ & 101.6 & 2.04 \\
$\mathrm{HR}$ & 165.6 & 2.24 \\
\hline
\end{tabular}


Table 7: Fitting parameters of the analytical R-curves.

\begin{tabular}{cccc}
\hline Strain rate regime & $\kappa$ & $n$ & $R^{2}$ \\
& {$\left[\mathrm{~mm}^{-1}\right]$} & {$[-]$} & {$[-]$} \\
\hline QS & 0.3794 & 4.247 & 0.9998 \\
HR & 0.3493 & 4.143 & 0.9998 \\
\hline
\end{tabular}

